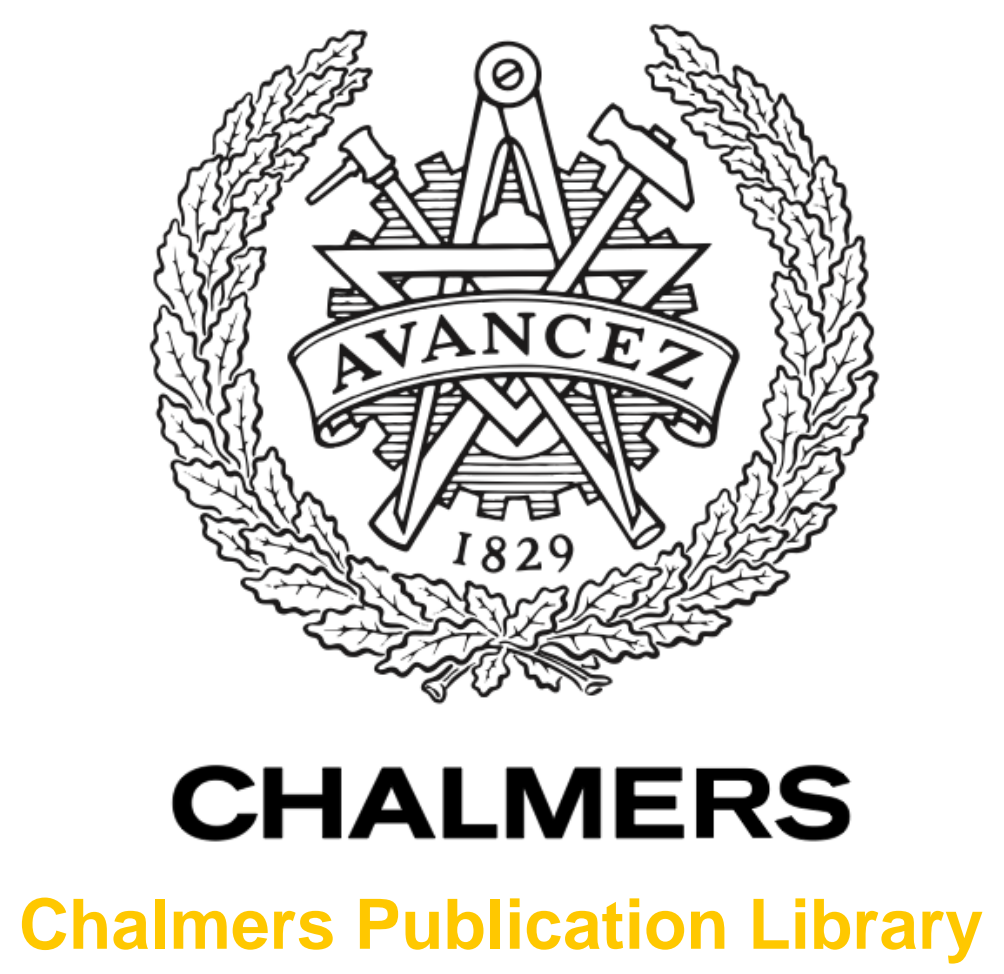

\title{
A multi-level structural assessment strategy for reinforced concrete bridge deck slabs
}

This document has been downloaded from Chalmers Publication Library (CPL). It is the author's version of a work that was accepted for publication in:

Structure and Infrastructure Engineering (ISSN: 1573-2479)

Citation for the published paper:

Plos, M. ; Shu, J. ; Zandi Hanjari, K. et al. (2017) "A multi-level structural assessment strategy for reinforced concrete bridge deck slabs". Structure and Infrastructure Engineering, vol. 13(2), pp. 223-241.

http://dx.doi.org/10.1080/15732479.2016.1162177

Downloaded from: http://publications.lib.chalmers.se/publication/245758

Notice: Changes introduced as a result of publishing processes such as copy-editing and formatting may not be reflected in this document. For a definitive version of this work, please refer to the published source. Please note that access to the published version might require a subscription.

Chalmers Publication Library (CPL) offers the possibility of retrieving research publications produced at Chalmers University of Technology. It covers all types of publications: articles, dissertations, licentiate theses, masters theses, conference papers, reports etc. Since 2006 it is the official tool for Chalmers official publication statistics. To ensure that Chalmers research results are disseminated as widely as possible, an Open Access Policy has been adopted.

The CPL service is administrated and maintained by Chalmers Library. 


\title{
A multi-level structural assessment strategy for reinforced concrete bridge deck slabs
}

\author{
Mario Plos ${ }^{1}$, Jiangpeng Shu ${ }^{1, *}, K$ amyab Zandi ${ }^{1,2}$, Karin Lundgren ${ }^{1}$ \\ ${ }^{1}$ Department of Civil and Environmental Engineering, Chalmers University of Technology, \\ 41296 Gothenburg, Sweden \\ ${ }^{2}$ Material Group, CBI Swedish Cement and Concrete Research Institute, \\ 50115 Borås, Sweden
}

Corresponding author: Email: shuj@chalmers.se

\begin{abstract}
This paper proposes a multi-level assessment strategy for reinforced concrete bridge deck slabs. The strategy is based on the principle of successively improved evaluation in structural assessment. It provides a structured approach to the use of simplified as well as advanced non-linear analysis methods. Such advanced methods have proven to possess great possibilities of achieving better understanding of the structural response and of revealing higher load-carrying capacity of existing structures. The proposed methods were used for the analysis of previously tested two-way slabs subjected to bending failure and a cantilever slab subjected to a shear type of failure, in both cases loaded with concentrated loads. As expected, the results show that more advanced methods yield an improved understanding of the structural response and are capable of demonstrating higher, yet conservative, predictions of the load-carrying capacity. Nevertheless, the proposed strategy clearly provides the engineering community a framework for using successively improved structural analysis methods for enhanced assessment in a straight forward manner.
\end{abstract}

Keywords: Multi-level assessment, Reinforced concrete slabs, non-linear finite element analysis, Load-carrying capacity, bending failure, shear type failure

\section{Introduction}

The existing infrastructure and built environment represent approximately $50 \%$ of the national wealth in most countries within Europe (Long, Henderson, \& Montgomery, 2001). Accordingly, the maintenance and repair of existing structures constitute an increasing part of the expenditure in the construction industry; around 50\% in Europe according to Long et al.(2011). Furthermore, change in societal needs such as increased transportation, densified cities and higher mobility, increase the demand for greater load-carrying capacity of the existing infrastructure, and calls for a reassessment of transport infrastructure in certain bridges. Bridge deck slabs are among the most exposed bridge parts and are often critical for the load-carrying capacity. Consequently, it is of high importance to have accurate methods for the assessment of load-carrying capacity and the evaluation of mechanical response in bridge deck slabs. With such methods, higher load-carrying capacity can be detected in the assessment of existing bridge deck slabs. Such methods will in turn lead to lower life cycle costs and reduced environmental impact.

A step-level procedure for the structural assessment of existing bridges has been proposed according to successively improved evaluation method integrated into the decision process 
(SB-LRA, 2007). At initial level, the assessment starts with calculations using ordinary design methods, with the assumption that the properties and condition of the structures are according to drawings. If safety cannot be assured, or if inspections reveal damage to the structure, the assessment can be enhanced through improved inspection, testing and more advanced analysis methods. For RC bridges where original drawings are missing, the material properties and amount and position of the reinforcement have to be obtained from sample tests and on-site measurements; see (SB-ICA, 2007). In the assessment of existing structures, it is often economic to use more accurate and detailed calculation models to better detect the real loadcarrying capacities, than what is motivated in the design of new structures. With non-linear finite element (FE) analysis, the structural response for a given set of actions can be simulated realistically. For reinforced concrete (RC) structures, the influence of concrete cracking and crushing, reinforcement yielding and the bond-slip interaction between concrete and reinforcement can be included. It has been stated that "non-linear FE analysis has the highest potential from all the analysis method for discovering any additional sources for load-carrying capacity” (SB-4.5, 2007) in the assessment of RC bridges.

However, even though the principle of successively improved evaluation for structural assessment is a sound strategy, it is only described in general terms in the literature. When used in engineering practice, it is left to bridge engineers to decide upon the most suitable method for each individual case. Consequently, there is a need for more detailed recommendations regarding suitable analysis methods at different assessment levels for each specific type of structure. Such recommendations may provide guidance to the overall structural analysis methods and resistance models to be used in combination, and may provide recommendations concerning modelling choices for the various levels of assessment.

The aim of this paper is to propose an assessment strategy for the structural assessment of $\mathrm{RC}$ bridge deck slabs and to demonstrate and examine the strategy in two case studies. The assessment strategy is based on the principle of successively improved evaluation involving structural analysis at five levels of detail and accuracy, ranging from simplified methods of the current dominate design methods to enhanced non-linear FE analysis.

The proposed method is demonstrated and validated in two case studies, representing different slab geometries and failure modes relevant to engineering practice. The case studies consist of (a) two-way slabs subjected to bending failure (Fall, Shu, Rempling, Lundgren, \& Zandi, 2014), and (b) a cantilever slab subjected to a combination of shear and punching failure (Vaz Rodrigues, 2007). Both types of slabs have been tested under concentrated loads.

The former experiments has previously been used for the development of modelling recommendations for non-linear 3D continuum FE analysis (Shu, Fall, Plos, Zandi, \& Lundgren, 2014b). The capability of the different proposed assessment levels to reflect the structural response and predict the load-carrying capacity of the slabs studied was evaluated by comparison to the test results.

\section{Structural Analysis for Assessment of Bridge Deck Slabs}

In engineering practice, structural analyses are performed to determine the action effects on the bridge deck slab, normally in terms of cross-sectional forces and moments. These are compared to corresponding (cross-sectional) capacities of the slab, determined using local resistance models. According to Eurocode 2 (EN 1992-1-1, 2004), a structural analysis can be performed at different levels of accuracy, from linear elastic to fully non-linear analysis. Traditionally, simplified linear two-dimensional (2D) beam or frame models have been used for the structural analysis of RC bridge deck slabs in combination with distribution widths 
from handbooks such as BBK 04 (Boverket, 2004). For RC slabs in buildings, methods based on plasticity, such as the yield line method (Johansen, 1972) and the strip method (Hillerborg, 1996) are applied. 3D grillage models (Hambly, 1976) have also been commonly used in the past for bridge deck ananlysis. Today, linear three-dimensional (3D) FE models are commonly used in engineering practice, see e.g., Rombach (2004) and Blaauwendraad (2010). Resistance models used are typically described in Eurocode 2 (EN 1992-1-1, 2004), ACI 318-11 (ACI Committee 318, 2011) or national regulations. If the structure is deteriorated, the effect on the structural performance can be included as a change in geometry (cross-section) and material properties of the concrete, reinforcement and their interface, see e.g., (Zandi Hanjari, Kettil, \& Lundgren, 2011).

For enhanced assessment, the non-linear response is preferably taken into account in the structural FE analysis and can be included at several different levels of detail. For RC slabs, the use of a bending plate or shell theory is effective. With shell elements and embedded (smeared) reinforcement (Schreppers, 2011) (CEB-FIP, 2008) to describe the RC slab, bending failure can be captured by the FE analysis. However, with available software for engineering practice, other types of failures like out-of-plane shear and punching are not reflected, but must be checked using separate resistance models. The MC2010 (CEB-FIP, 2013) provides resistance models at several levels of accuracy for different potential failure modes, such as shear, punching and anchorage failures.

With continuum (solid) elements to represent slabs, considerably larger FE models and longer computational times are obtained. On the other hand, inclined cracking and out-ofplane shear and punching failures can be captured in the structural analysis. By also including the bond-slip relation for the reinforcement-concrete interaction, anchorage failures can be captured and with a sufficiently dense element mesh a detailed picture of the cracking can be obtained.

Non-linear structural analysis has also proven to be capable of describing the behavior of deteriorated RC structures in a comprehensive way. Provided that appropriate constitutive models are adopted, the effect of the deterioration on the reinforcement, concrete and their interaction can be realistically accounted for. The effect of concrete cracking, due to such as internal frost damage or alkali-silica reaction, can be taken into account in the FE analysis by adopting reduced-material strength and stiffness. Corrosion-induced or frost-induced spalling can be accounted for by reducing the concrete cross section. When the bond-slip relation for the reinforcement-concrete interaction is included in the analysis, the effect of the deterioration on bond needs also to be accounted for; see Lundgren et al. (2012).

There are several references available with recommendations for a 3D linear FE analysis of RC slabs, e.g., Rombach (2004) and Blaauwendraad (2010). Detailed recommendations for modelling and designing of RC slabs based on a linear FE analysis are given in Pacoste et al. (2012). For a non-linear analysis, there is less literature available to provide practical recommendations. Rijkswaterstaat (2012) provides guidelines for non-linear FE analysis of RC girder members and Broo et al. (2008) presents a guide to the non-linear FE modelling of shear and torsion in concrete bridges. Belletti et al. (2014) carried out non-linear FE analyses of RC slabs at different levels of approximation according to MC 2010 (CEB-FIP, 2013). Amir (2014) investigated compressive membrane action using non-linear FE analyses and obtained similar results as experiments. Modelling recommendations of non-linear analysis of RC slabs using 3D continuum finite elements was proposed by Shu et al. (2014b) and was evaluated for two-way slabs subjected to bending failure.

The safety format commonly used in design as well as in assessment is the partial safety factor method. This is suitable for a normal two-step procedure in which the action effect is 
compared with the resistance at a component or cross-sectional level. When a non-linear analysis is used, one or several possible failure modes are integrated into the structural analysis, and the resistance is evaluated in a one-step procedure at the structural level. Hereby, the partial safety factor method is not suitable. Instead, safety formats based on global safety factors should preferably be used. Eurocode 2 (EN 1992-2, 2004) provides some directions in this area; the method is further elaborated in the MC 2010 (CEB-FIP, 2013). Schlune et al. (2011) showed deficiencies in how model uncertainties were treated in these methods for difficult-to-model failure modes, such as bending failures in skew directions and shear type failures; hence the methods in Eurocode (EN 1990, 2002) and MC 2010 (CEB-FIP, 2013) should be applied with care for such cases.

\section{A Multi-Level Structural Assessment Strategy}

The multi-level assessment strategy proposed in this paper for RC bridge deck slabs is based on the principle of successively improved evaluation in structural assessment (SB-LRA, 2007). In Figure 1, a flow diagram for the assessment process is illustrated. It starts with an initial assessment based on available documentation, using simplified analysis methods similar to those used in design. If the requirements are not fulfilled, it is possible to move to more enhanced assessment, after evaluation of the economical, societal and environmental consequences of proceeding or alternatively finishing the assessment. The enhanced assessment can include gathering of improved information regarding the in-situ conditions through inspections, monitoring and testing, or deeper studies of the documentation. Such assessment often consists of more advanced structural analyses and resistance models that are more accurate and reliable. 


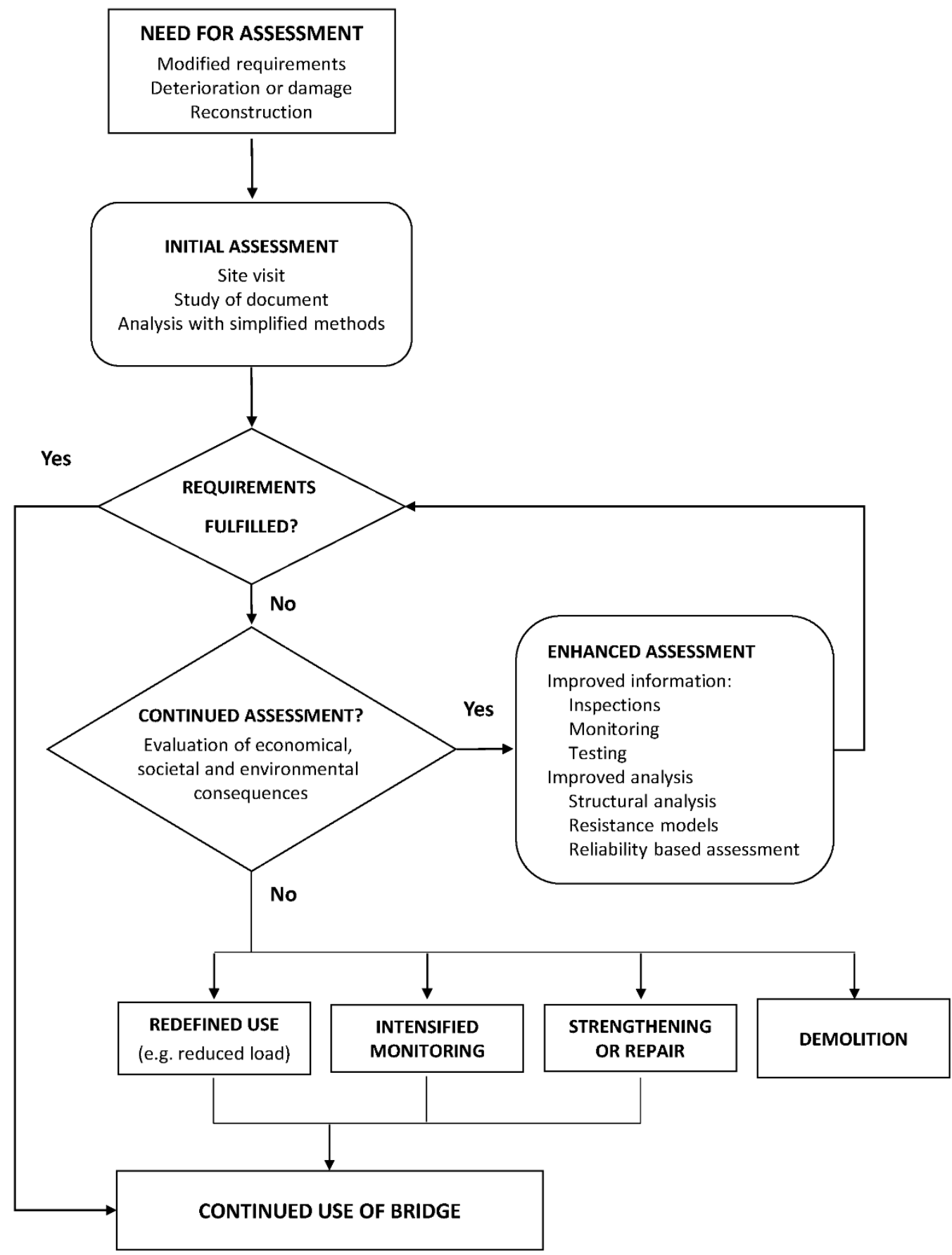

Figure 1. Flow diagram for structural assessment based on the principle of successively improved evaluation

After performing the enhanced assessment, it is re-evaluated whether to proceed, and which methods that should be used to improve the assessment further. Finally, the assessment results in a decision whether it is possible to continue the use of the bridge, and if this is the case, whether intensified monitoring, strengthening or repair would be needed.

The proposed multi-level assessment strategy focuses on enhanced assessment through improved structural analyses and resistance evaluations. For RC bridge deck slabs, different assessment levels according to Figure 2 maybe be distinguished. Evaluation of the structural response and load-carrying capacity can be made with structural analysis at levels ranging 
from simplified methods (I) over the currently dominant design methods based on linear FE analysis (II) to non-linear FE analysis at different levels of detailing (III - V). If the failure mode in question is not reflected in the analysis, the structural analysis needs to be combined with local resistance models. It is desirable that the models for structural analysis and for the determination of local resistance are, as far as possible, at equivalent levels of accuracy. In the assessment process, Figure 1, it is reasonable to use analysis on level I or II for the initial assessment. If the assessment is continued with enhanced methods, improved structural analysis and resistance models on higher assessment levels (II to V) can be utilized successively within to the "loop" for continued assessment indicated in the figure.

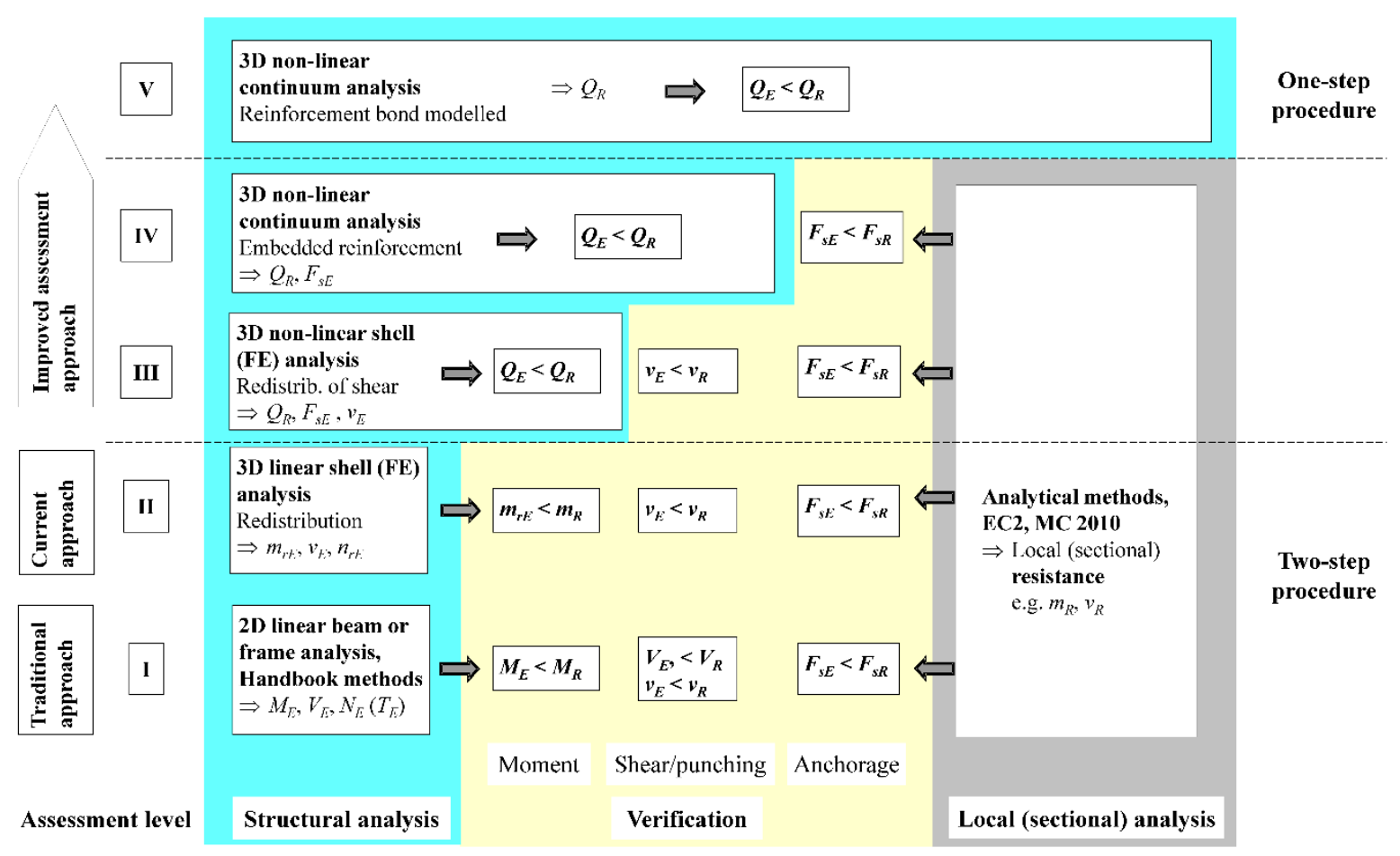

Figure 2. Scheme for multi-level assessment of reinforced concrete bridge deck slabs

The proposed assessment levels are briefly described below, and are exemplified by two case studies in Sections 4 and 5.

\subsection{Level I: Simplified Analysis Methods}

At this level, the structural system is commonly simplified to 2D beam or frame models with a pre-assumed load distribution along the main directions. For a RC slab, this can be generalised as the strip method (Hillerborg, 1996). In both cases, the structural model is based on the lower bound theorem of plasticity (Hillerborg, 1996). The analysis can be complemented by the yield line method (Johansen, 1972), giving an upper bound for the plastic load-carrying capacity. The limited plastic deformation capacity of the slab can be accounted for by limitations of the load distribution widths, e.g., BBK 04 (Boverket, 2004). For two-way spanning slabs, there are also solutions tabulated in handbooks for the distribution of load effects (BBK 04, 2004).

The load effects are compared with corresponding resistances determined by local models for bending, shear, punching and anchorage of reinforcement. Common design resistance models are used, as described in e.g., the Eurocode 2 (EN 1992-1-1, 2004), ACI 318-05 (ACI Committee 318, 2011) or national regulations. 


\subsection{Level II: 3D Linear Shell (FE) Analysis}

Here, the structural analysis is performed using 3D FE models, most often based on shell or bending plate theory. The analysis is performed assuming linear response to be able to superimpose the effect of different loads, in order to achieve the maximum load effects in terms of cross-sectional forces and moments throughout the structure for all possible load combinations. Since both geometrical simplifications and the assumption of linear material response result in unrealistic stress concentrations, and because the bars are often arranged in strips with equal bar diameter and spacing, the redistribution of the linear cross-sectional forces and moments are necessary. Recommendations on redistribution widths for bending moments and shear forces are given in Pacoste et al. (2012). The structural analysis can be seen as "linear elastic with limited redistribution" according to Eurocode 2 (EN 1992-1-1, 2004). The load effect is then compared with corresponding resistance in similar way as at level I.

\subsection{Level III: 3D Non-linear Shell FE Analysis}

In a non-linear analysis, the loads are successively increased until failure of the structure is reached. In practice, due to the excessive amount of work it would require, non-linear analysis cannot be performed for all possible load combinations, but only for the most critical loads determined previously in the assessment process. At this assessment level, shell (or bending plate) finite elements are used. The reinforcement is included in the FE model but assumed to have perfect bond to the concrete; it is preferably modelled as embedded reinforcement (Schreppers, 2011) layers in the shell elements, strengthening the concrete in the direction and at the level of the reinforcement bars. In such a model, bending failures will be reflected in the analysis, whereas out-of-plane shear, punching, or anchorage failures are not reflected. Instead they must be checked by local resistance models. With this level of accuracy on the structural analysis, resistance models at higher levels of approximation according to MC2010 (CEB-FIP, 2013) are preferably used. For shear type failures, models taking into account the in-plane stress-state from the non-linear analysis are recommended.

\subsection{Level IV: 3D Non-linear FE Analysis with Continuum Elements and Fully Bonded Reinforcement}

Here, the non-linear analysis is performed using 3D continuum elements representing the concrete. Similarly to level III, the reinforcement is assumed to have perfect bond and no slip to the concrete (Schreppers, 2011); embedded reinforcement layers can be used in coarse FE meshes, while individual (embedded) bars may be preferred in dense meshes with elements smaller than the reinforcement bar distances, to better reflect the crack pattern. In such an analysis both bending and shear type failures including punching can be reflected. However, anchorage failures need to be checked with the help of separate resistance models.

\subsection{Level V: 3D Non-linear FE Analysis with Continuum Elements Including Reinforcement Slip}

Compared to level IV analysis, the reinforcement is modelled using separate finite elements (Schreppers, 2015). Furthermore, the bond-slip behaviour of the interface between the reinforcement and the concrete is included. With a fine mesh, individual cracks can be studied and anchorage failure can be reflected in the analysis. With this level of accuracy in the structural analysis, the intention is that no major failure modes should be necessary to check using separate resistance models.

When the structure is deteriorated due to causes such as reinforcement corrosion, frost damage or alkali-silica reaction, the structural effect of the deterioration needs to be 
accounted for in the analysis. At levels I and II, the deterioration will affect the structural analysis only if the stiffness relations are altered, whereas the resistance calculations are more directly influenced. With non-linear structural analysis at levels III - V, lowered material strength, concrete cover spalling and deteriorated reinforcement-concrete interaction may directly be included in the analysis. Recommendations on how to take into account the effect of deterioration can be found in Zandi Hanjari et al. (2011c, 2013) for reinforcement corrosion and in Zandi et al. (2011a,b) for frost damage.

When global buckling might be critical, this can be taken into account in analyses at levels III -V by including geometric non-linearity and initial imperfections in the FE analysis. The level of assessment that is needed in each individual case is governed by the local failure mode limiting the deformations. For most cases, when bending is limiting the deformations, analysis at level III will be sufficient.

For each level of assessment, a relevant safety format should be used. When a two-step procedure is used to determine the load-carrying capacity, as at levels I and II, the partial factor method is normally used. For non-linear analysis, using a one-step procedure to determine the load-carrying capacity at the structural level, safety formats based on global safety factors according to MC2010 (CEB-FIP, 2013) are recommended. This applies to level $\mathrm{V}$ as well as levels III and IV for the types of failures reflected in the non-linear analysis. When failure modes not reflected in the analysis are checked using separate resistance models, using the partial factor method is appropriate. When safety formats based on global safety factors are used, and bending failures in skew directions and shear type failures govern the capacity, the modelling uncertainty used should be given special attention since the values given in MC2010 (CEB-FIP, 2013) might be too low, Schlune et al. (2011).

Before proceeding to a more advanced level of assessment, it is important to judge the benefits of the more accurate evaluation with respect to the increased cost in terms of additional working hours and computation time. For example, when evaluating a simple structure like a simply supported slab with distributed load, spanning in one direction, it is not likely to gain much by going beyond level I or II; for a two-way spanning slab failing due to bending, it is probably not possible to show much higher load-carrying capacity when going beyond level III.

Even though assessment at more enhanced levels provide improved understanding and higher detectable load carrying capacity, the increased cost in terms of additional working hours and computation time must be weighted in relation to what can be gained before choosing whether to proceed with analyses at higher levels. The benefit of performing more advanced structural analysis must also be weighed against other methods to improve the assessment, e.g., improved inspections, monitoring and testing and reliability-based assessment. The aim of the assessment must be clear to help determine which method and assessment level that is adequate for the current structure. To facilitate this goal, the proposed multi-level assessment strategy may be of benefit in evaluating existing RC slabs.

For the case studies below, the different assessment levels were compared. The predicted load-carrying capacities were calculated using mean values of material parameters at all different levels. In this way, the different safety formats or chosen safety levels do not influence the comparison. Instead, it is the capability of the structural analysis and resistance models to predict the load-carrying capacities that is evaluated and compared to test results. 


\section{Case 1: Application to Two-way Slabs Subjected to Bending Failure}

\subsection{Experiment}

Fall et al. (2014) carried out a series of tests on two-way slabs. In a larger test series, three specimens with the same dimensions were tested. The specimens were octagonal slabs (80 $\mathrm{mm}$ in thickness) supported on four edges, by five rollers each, and subjected to a point-load at the centre, see Figure 3 (left). The loading was deformation controlled and the reaction forces were measured by strain gangues on the roller supporting the slab. Details regarding the monitoring campaign can be found in Fall et al. (2014). The compressive and tensile strength of the concrete and the tensile strength of steel reinforcement were determined through material tests. The reinforcement, consisting of $6 \mathrm{~mm}$ ribbed bars, was twice as dense at the first bottom layer $(s=98 \mathrm{~mm})$ as at the second $(s=196 \mathrm{~mm})$.
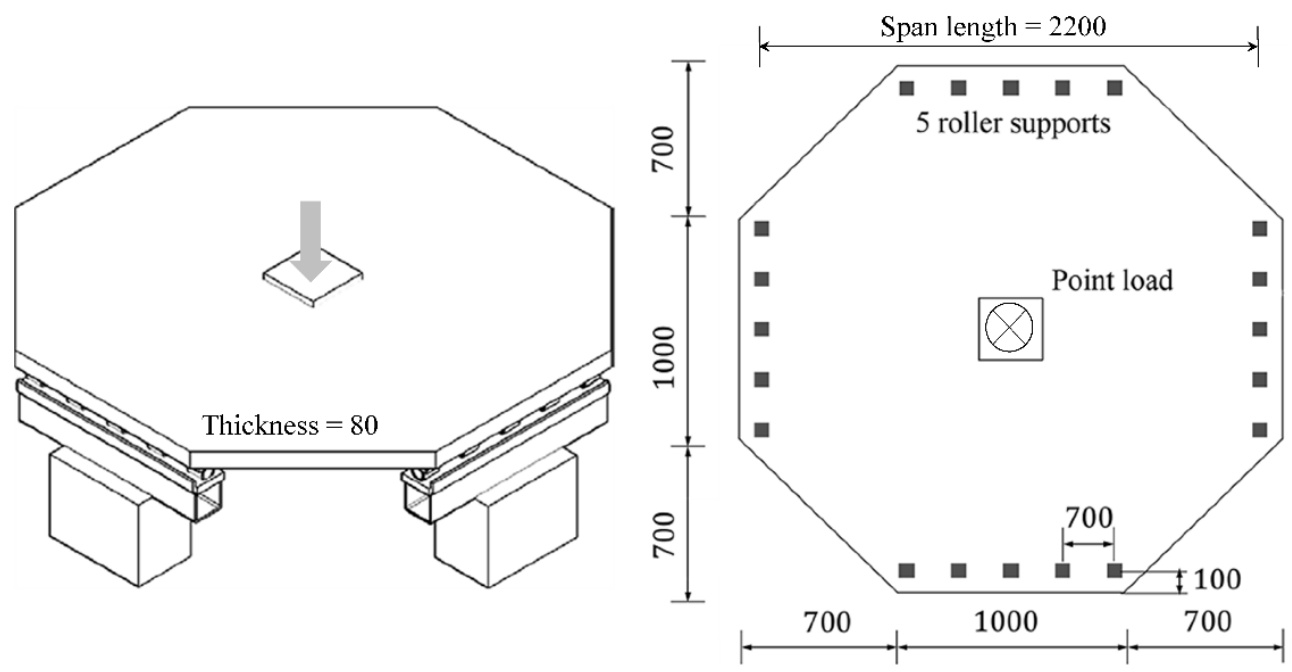

Figure 3. Setup of the test (left) and dimension of tested slab (right); dimensions in mm, Fall et al. (2014).

The three slabs tested showed very similar results. In the tests, cracking started when the load was $27 \mathrm{kN}$ on the average $(27 \mathrm{kN}, 27 \mathrm{kN} \& 27 \mathrm{kN}$ for the three samples), followed by bending hardening. The slabs failed at the ultimate load of $\mathrm{P}_{\text {u.exp }}=70 \mathrm{kN}$ on the average $(69 \mathrm{kN}, 69 \mathrm{kN} \& 71 \mathrm{kN}$ for the three samples) with a rupture of reinforcement bars; the tests were aborted when two bars had ruptured (Fall et al., 2014).

\subsection{Analysis at Different Assessment Levels}

To analyse the response of the two-way RC slabs, the finite element software DIANA 9.4.4 (TNO, 2012) was used to model the slabs at all levels. According to the previous study (Shu, 2015), the mesh size has been proven to have minor impact to the analyses results when the presented modelling method is used.

\subsubsection{Material Models for Concrete and Reinforcement}

In the following section, the two-way slabs were assessed at different levels according to the strategy. In all calculations, mean values of material parameters from the tests (Fall et al., 2014) were used, see Table 1. 
Table 1. Mean values of material parameters for the two-way slabs (Fall et al., 2014).

\begin{tabular}{|l|l|l|r|}
\hline \multicolumn{2}{|l|}{ Parameter of concrete } & \multicolumn{3}{|c|}{ Parameter of reinforcement steel } \\
\hline Elastic modulus & $E_{c}=24.5 \mathrm{GPa}$ & Elastic modulus & $E_{s}=210 \mathrm{GPa}$ \\
\hline Poisson's ratio & $v=0.15$ & Poisson's ratio & $v=0.2$ \\
\hline Compressive strength & $f_{c m}=50.9 \mathrm{MPa}$ & Yield strength & $f_{y}=550 \mathrm{MPa}$ \\
\hline Tensile strength & $f_{c t m}=2.7 \mathrm{MPa}$ & Ultimate strength & $f_{u}=666 \mathrm{MPa}$ \\
\hline
\end{tabular}

For the material model applied to the non-linear FE analysis at level III-V, concrete was modelled using a fracture energy based total strain rotating crack model (TNO, 2012). In tension, a smeared rotating crack model (Rots, 1988) was used. In this approach, the crack width $w$ is related to the crack strain $\varepsilon_{c r}$ perpendicular to the crack via a characteristic lengththe crack band width $h_{b}$. The advantage is that the formulation remains local and the algorithmic structure of the finite element code requires only minor adjustments, limited to the part of the code responsible for evaluations of the stress (and stiffness) corresponding to a given strain increment (Jirásek, 2012). The crack band width was determined differently depending on the bond-model for reinforcement (Shu, Fall, Plos, Zandi, \& Lundgren, 2014a) and an example of the tension softening curve can be found in Figure 4 (left).
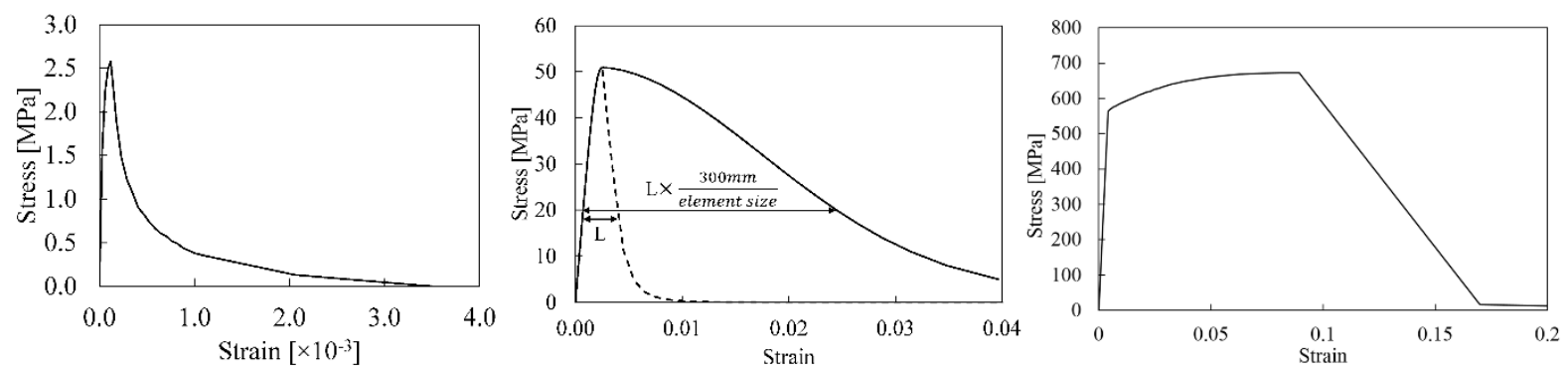

Figure 4. Stress-strain relations used for the uniaxial response of concrete in tension (left; of concrete in compression (middle); and Von Misses plasticity model of reinforcement steel (right)

The behaviour of concrete in compression was described by an isotropic damage constitutive law. When the stress-strain relationship was used in numerical analyses, the localization of deformation in compressive failure needs to be taken into account. The compression softening behaviour is related to the boundary conditions and the size of the specimen (Mier, 1984). Consequently, the stress-strain relation used has been calibrated by measurements of compression tests on $300 \mathrm{~mm}$ long cylinders. The softening branch needs to be modified for the concrete element size used in the FE model. Thus, the stress-strain curve according to Thorenfeldt (1987) was modified to fit the concrete element size (Zandi Hanjari, Kettil, \& Lundgren, 2013), resulting in a uniaxial stress versus strain response as shown in Figure 4 (middle). The other material properties used were identical to Table 1.

The behaviour of the reinforcement was described by a Von Mises plasticity model, including strain hardening, using values as obtained from material tests, see Figure 4 (right).

\subsubsection{Level I: Simplified Analysis Method}

At the initial level of structural assessment, the load-carrying capacity with respect to bending failure was estimated using the strip method (Hillerborg, 1996) by assuming the load was carried by slab strips in both $x$ and $y$ directions; see Figure 5 (a) as well as the yield line method (Johansen, 1972); see Figure 5 (b). The failure load with respect to one way shear and punching were checked according to Eurocode 2 (EN 1992-1-1, 2004). The results of this 
calculation are displayed in Table 2. The anchorage was also checked according to Eurocode 2 (EN 1992-1-1, 2004), i.e. the reinforcing bars are anchored so that the bond forces are safely transmitted to the concrete avoiding longitudinal cracking or spalling.

Table 2. Calculated load-carrying capacity for bending, one-way shear and punching shear for two-way slabs; *indicates the critical value

\begin{tabular}{|l|l|}
\hline Resistance with respect to: & Load-carrying capacity $Q_{u}(\mathrm{kN})$ \\
\hline Bending capacity (Strip method) & $22.3^{*}$ \\
\hline Bending capacity (yield line theory) & 37.9 \\
\hline One-way shear & 111.7 \\
\hline Punching shear (EC2) & 110.6 \\
\hline
\end{tabular}

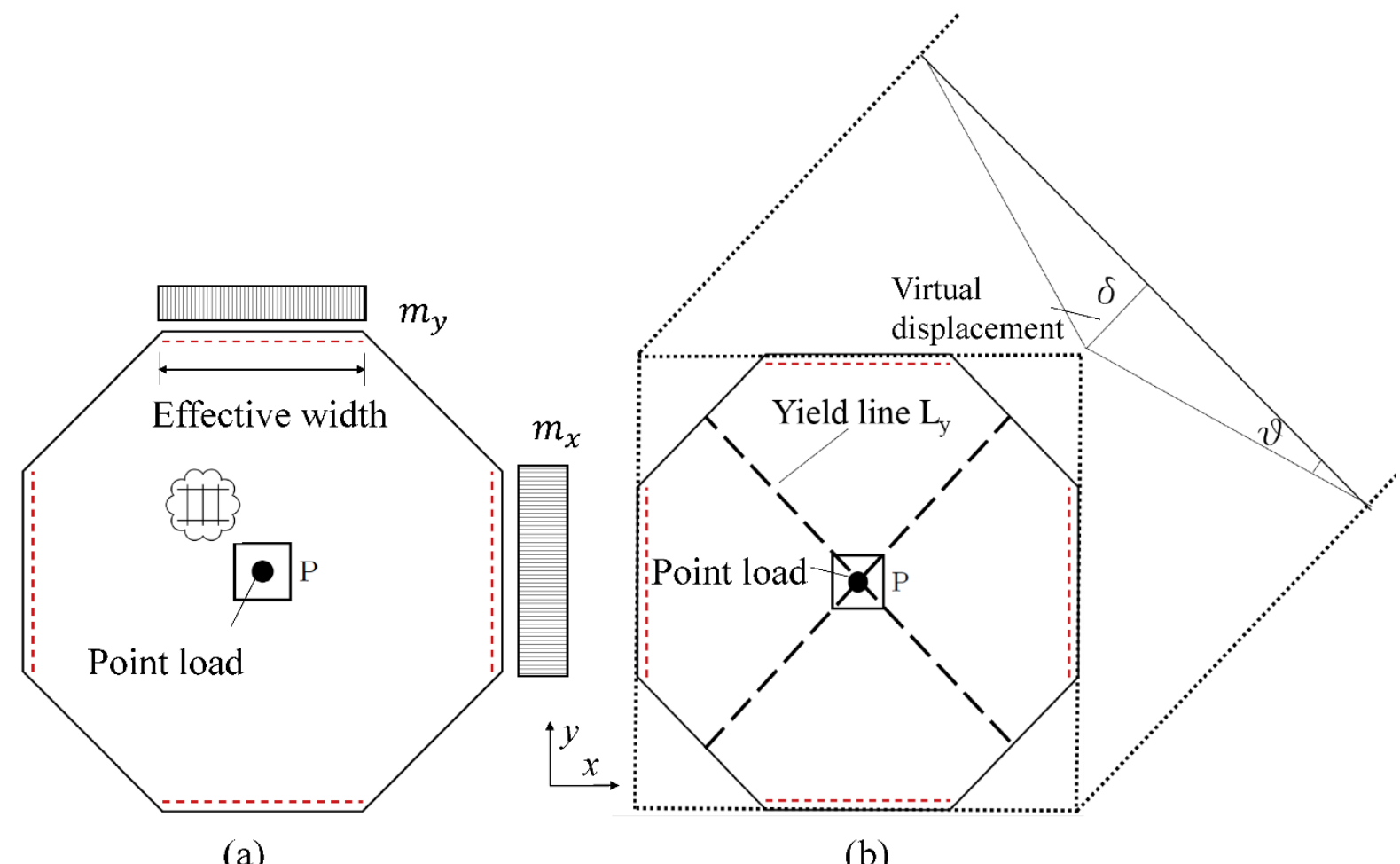

Figure 5. Calculation models for the two-way slabs using yield line method (a) and strip method (b)

\subsubsection{Level II: 3D Linear Shell (FE) Analysis}

At level II, a 3D linear FE model of a quarter of the slab was defined, as seen in Figure 6 (left). The concrete slab was modelled with 8-noded rectangular shell elements of the size $40 \mathrm{~mm} \times 40 \mathrm{~mm}$. Symmetry boundary conditions were applied to the symmetry lines and the roller supports were modelled by preventing translations in vertical direction and horizontally along the rollers. A unit pressure load equal to $1 \mathrm{kN}$ was applied to the centre area of the slab, at the position of the loading plate.

The linear FE analysis results in a moment field consisting of bending moments, see Figure 6 (right). At the ultimate limit state, the forces in each main reinforcement layer multiplied by the corresponding inner lever arms will result in bending moment resistances. These moment resistances must balance the complete linear moment field, including the torsional moment. Methods to determine the sectional forces and moments for design of slab reinforcement are found in handbooks (Pacoste et al., 2012). The reinforcement moments $m_{r x}$ and $m_{r y}$ for the 
design of reinforcement in the two perpendicular reinforcement directions $x$ and $y$ can be defined according to

$$
\left\{\begin{array}{l}
m_{r x}=m_{x}+\mu\left|m_{x y}\right| \\
m_{r y}=m_{y}+\frac{1}{\mu}\left|m_{x y}\right|
\end{array}\right.
$$

where $m_{x}$ and $m_{y}$ are the bending moments in the $x$ and $y$ directions respectively. Furthermore, $m_{x y}$ is the torsional moment and $\mu$ is a factor that can be chosen with respect to practical considerations, here equal to 1 . Owing to the capacity of plastic redistributions in concrete structures, the reinforcement moments can be redistributed over a certain width, here denoted w.
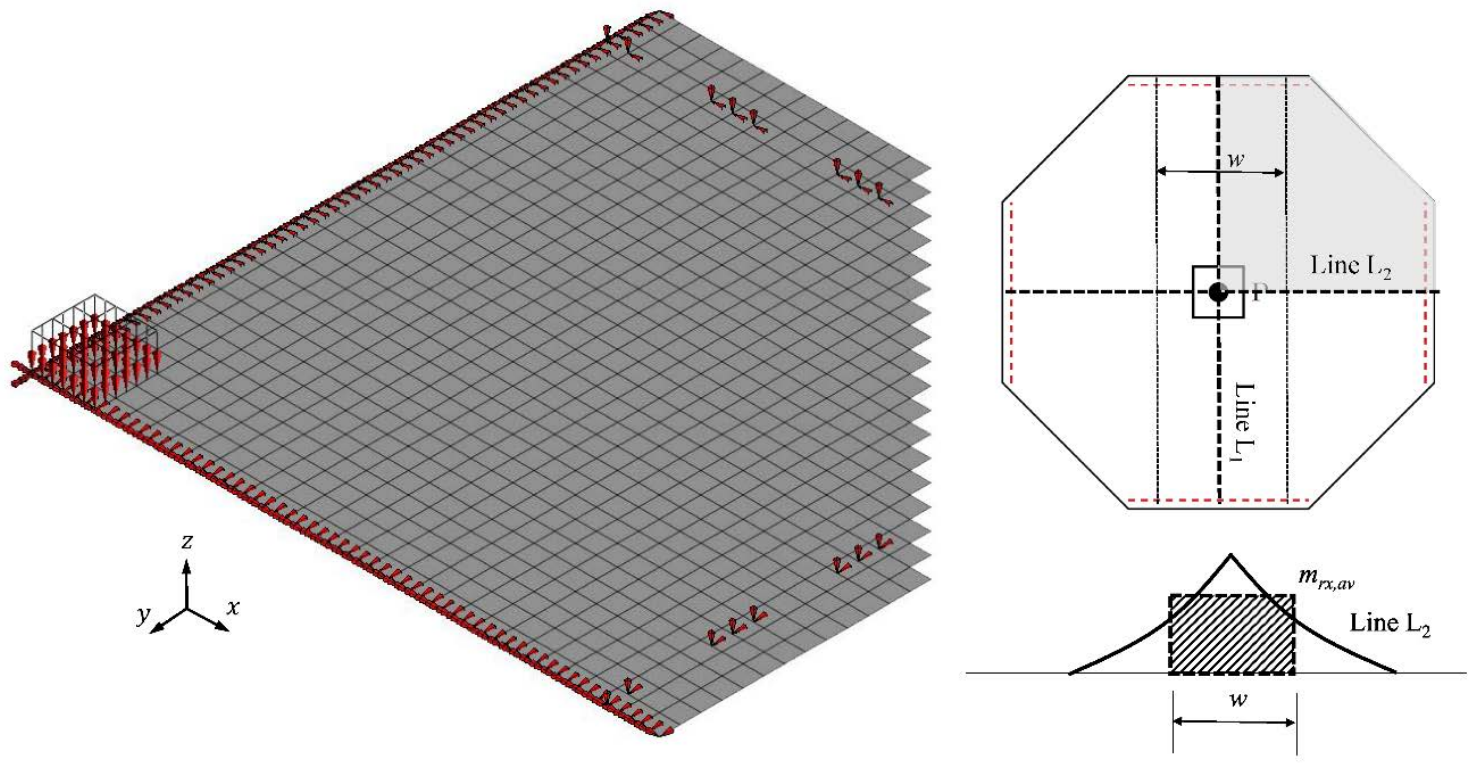

Average of moment distribution

Figure 6. Linear shell element model of the two-way slabs, for level II (left) and schematic moment distribution along yield lines (right)

Figure 6 (right) schematically shows in principle the distribution of $m_{r x}$ along line $L_{2}$ in a direction orthogonal to the moment direction (in this case the $y$ direction). Within the redistribution width $w$, the linear moment distribution $m_{r x}$ along line $L_{2}$ is replaced by a constant distribution with the average value $m_{r x, a v}$, computed as

$$
m_{r x, a v}=\frac{1}{w} \int_{0}^{w} m_{r x} d y
$$

The redistribution width is limited by the rotation capacity of the slab, which can be represented by the ratio between the compression zone height, $x_{u}$, over the effective depth of the cross-section, $d$. According to (Pacoste et al., 2012), the redistribution width for the slab studied can be calculated by an interpolation between 


$$
w=\left\{\begin{array}{cl}
\frac{L_{c}}{2}, & \text { for } \frac{x_{u}}{d}=0.15 \\
\min \left(5 h, \frac{L_{c}}{5}\right), & \text { for } \frac{x_{u}}{d}=0.0
\end{array}\right.
$$

In the above equations, $h$ is the height of the section and $L_{c}$ is the characteristic span width, in this case $h=80 \mathrm{~mm}, L_{c}=2200 \mathrm{~mm}$ and $x_{u} / d=0.05$ which yields $w=638 \mathrm{~mm}$ by interpolation. The concentrated loading capacity of the slab with respect to bending was calculated as

$$
P_{u}=\frac{m_{R x}}{m_{r x . a v}} \times 1 k N=\frac{8.9}{201.6} \times 1 k N=44.3 k N
$$

Equation 4

$m_{R x}$ is the bending resistance of the slab strip calculated for the currentreinforcement ratio. The capacity with respect to one-way shear, punching and anchorage failure was checked according to the linear FE analysis and were found not to be critical.

\subsubsection{Level III: 3D Non-linear Shell FE Analysis}

For a non-linear structural analysis at level III, the slab was modelled with shell elements using a similar mesh as for level II, see Figure 7. A Simpson integration scheme was used with 9 integration points over the thickness together with Gauss integration with $2 \times 2$ integration points over the shell area. The reinforcement was included in the model as fully bonded embedded reinforcement, in this case as individual rebars with the same layout as in reality. Instead of applying equally distributed load as at level II, a steel plate was added to the model. All nodes of the steel plate were tied to the centre node using "tying elements" so that they all had the same displacement in z direction. In this way displacement control can be used for the node at the centre of the slab in the loading procedure. The analysis was carried out using a regular Newton-Raphson iteration method based on force and energy convergence criteria, with a tolerance of $1 \mathrm{e}-2$. The analysis finished when the analysis could not achieve convergence due to reinforcement rupture. The load-carrying capacity obtained was $P_{u}=60.7$ $\mathrm{kN}$. The risk of shear and punching failures as well as anchorage failure were checked separately and found not to be critical. 


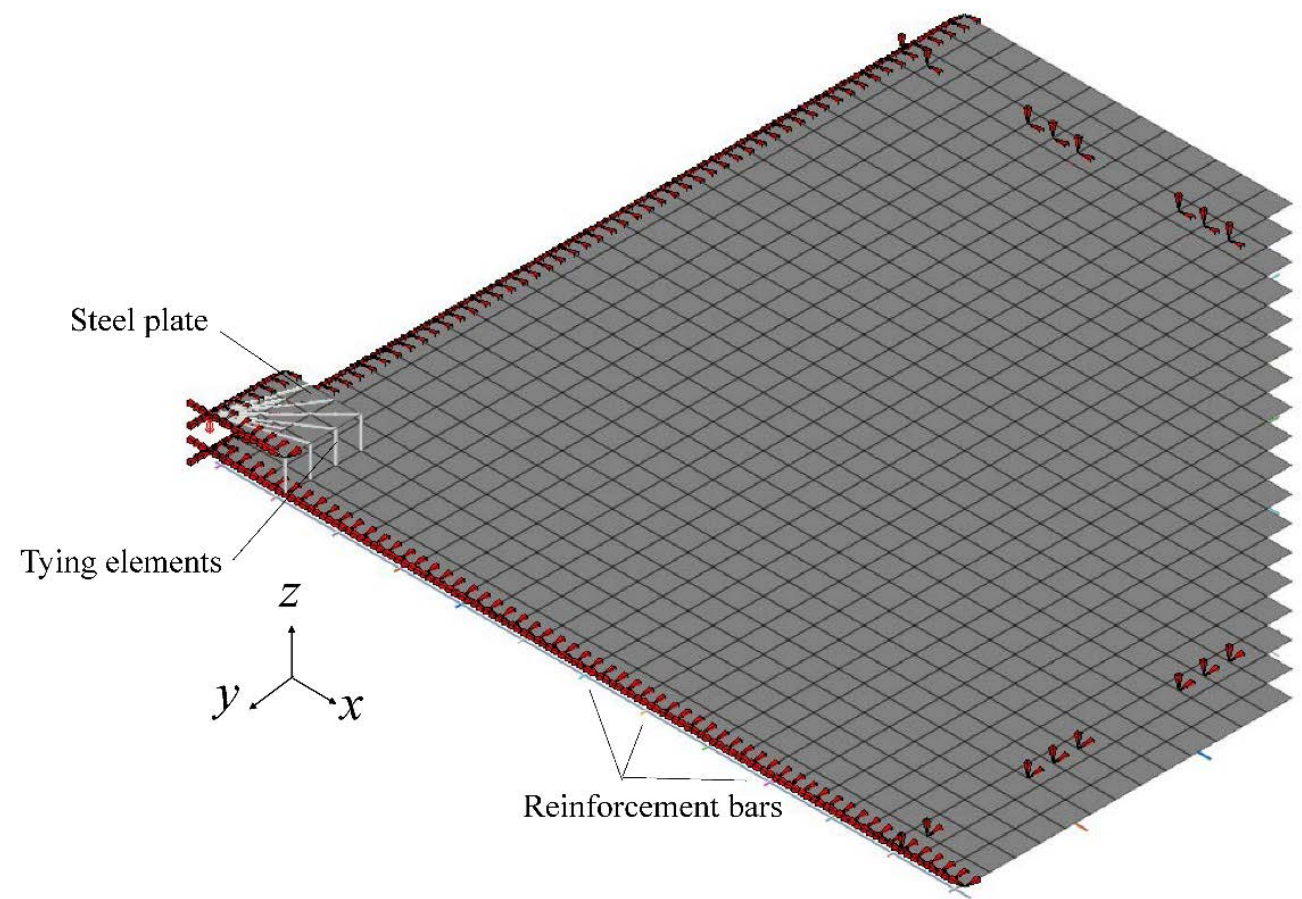

Figure 7. Non-linear shell element model of the two-way slabs, for level III

\subsubsection{Level IV: 3D Non-linear FE Analysis with Continuum Elements and Fully Bonded Reinforcement}

For Level IV, a detailed 3D model with continuum elements was defined, as displayed in Figure 8. In (Shu et al., 2014b) such a model proved to be capable of predicting the loadcarrying capacity of the same two-way slab reasonably well. In the FE model, the steel plates at the supports were included and interface elements were used between the concrete and the steel plates to describe friction. To model the boundary conditions provided by the roller supports, the translation of the nodes representing the centre of the rollers under the steel plates were fixed in both vertical direction and along the roller axis. The translation of all nodes at the symmetry faces were fixed in the perpendicular direction. In this model, the geometric non-linearity with Total Lagrange description was included because a large deflection $(120 \mathrm{~mm})$ of the tested slab was observed. First order 8-noded brick elements, $40 \times 40 \times 10 \mathrm{~mm}$ (length $\times$ width $\times$ height) were used. Further refinement of the element mesh was found to have minor impact on the analyses results (Shu et al., 2014a). The analysis was carried out using a regular Newton-Raphson iteration method based on force and energy convergence criteria, with a tolerance of 2e-2. The analysis finished when convergence could not be achieved due to bending failure limited by reinforcement rupture. The load-carrying capacity obtained was $P_{u}=66.7 \mathrm{kN}$. Since perfect bond was assumed for the interaction between the reinforcement and the concrete, the anchorage failure was also checked according to Eurocode 2 (EN 1992-1-1, 2004) and found to be non-critical. 

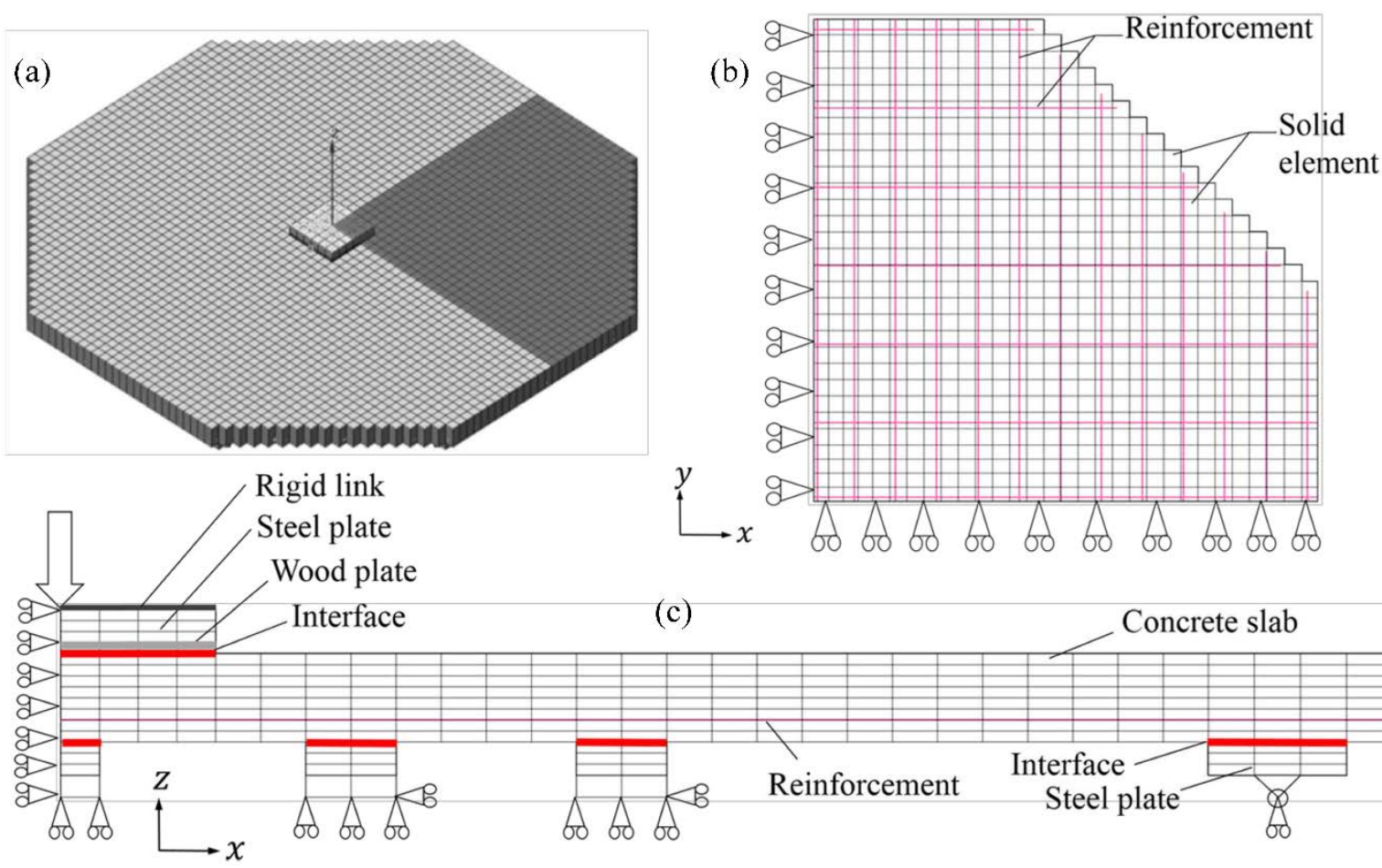

(c)

Figure 8. Non-linear continuum element model of the two-way slabs for level IV and V; (a) isometric view with the modelled quarter of the slab marked; (b) top view (c) side view

\subsubsection{Level V: 3D Non-linear FE Analysis with Continuum Elements Including Reinforcement Slip}

The models at level V and IV were identical except for the bond of reinforcement. Instead of using fully bonded reinforcement as at Level IV, a bond-slip behaviour was included to better describe the interaction between reinforcement and concrete. When the bond-slip model was used, 2-noded truss elements for the reinforcement were connected to the concrete elements by line interface elements; this was done automatically by the FE-program during preprocessing. These interface elements described a bond-slip behaviour in terms of a relation between the traction and the relative displacement along the bars. The analytical bond-slip relation for unconfined concrete under "good" bond conditions given in the MC1990 (CEBFIP, 1993) was assumed, see Figure 9, i.e. with the notation used in MC1990, $s_{1}=\mathrm{s}_{2}=0.6 \mathrm{~mm}, \mathrm{~s}_{3}=1.0 \mathrm{~mm}, \tau_{\max }=14.26 \mathrm{MPa}$ and $\tau_{f}=2.14 \mathrm{MPa}$. The analysis finished after reinforcement rupture. The load-carrying capacity obtained was $P_{u}=62.5 \mathrm{kN}$.

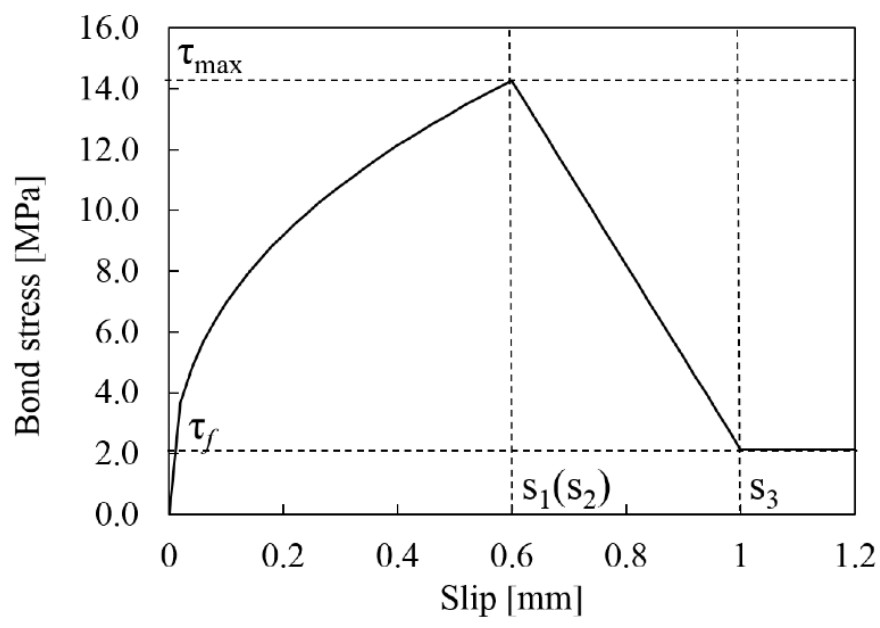


Figure 9. Bond-slip relation used for the interaction between concrete and the ribbed reinforcement bars for two-way slabs (CEB-FIP, 1993)

\subsection{Results and discussion}

\subsubsection{Structural behaviour}

The load-carrying capacity of the two-way slab at level I-II and the load-deflection curves from non-linear FE analyses at level III-V and from one of the tests are displayed in Figure 10 . Before the cracking load $(\approx 30 \mathrm{kN})$ reached, the response from both test and analyses illustrates an elastic behaviour. After cracking, a clear bending hardening behaviour followed. The ultimate capacity of the slab was reached when the deflection at the centre of the slab was almost $120 \mathrm{~mm}$.

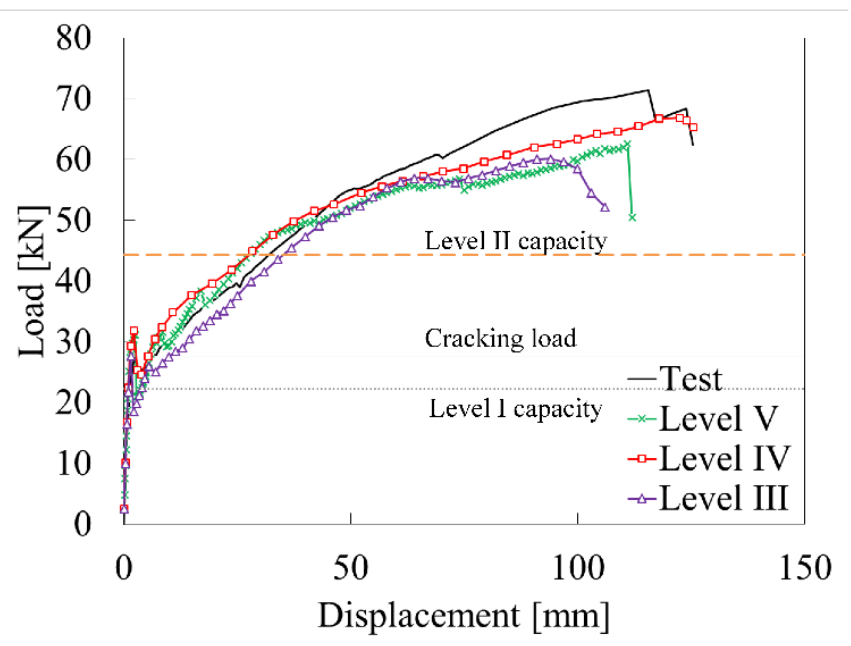

Figure 10. Load-deflection response and bending resistance of the two-way slabs

Figure 11 shows crack patterns from one of the tests and the non-linear analyses. It is evident that the load-deflection behaviour in the non-linear analyses well reflects the experimental tests. In the experiments, the slabs failed at an average ultimate load of $70 \mathrm{kN}$ with rupture of reinforcement bars. Several flexural cracks propagated from the centre in the diagonal direction, see Figure 11. The crack pattern was well predicted by the models at level III-V, and coincides with the failure mechanism assumed in the yield line method at level I. 


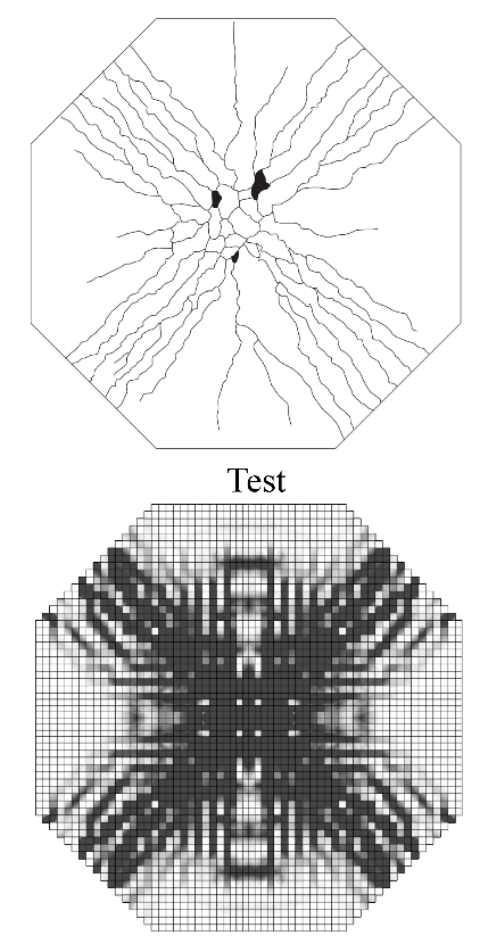

Level IV

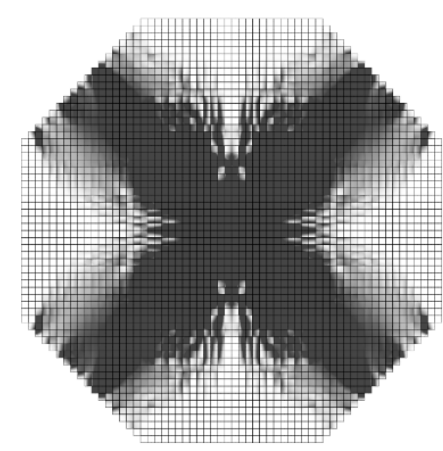

Level III

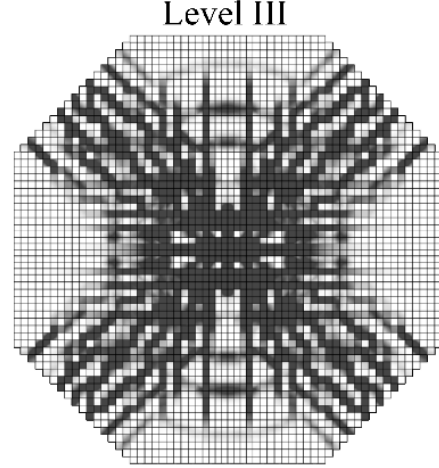

Level V

Figure 11. Crack pattern from experiment (CR1) and the strain based crack pattern from analysis of the two-way slabs at $95 \%$ of the ultimate load $(\varepsilon=2 \mathrm{e}-3$ indicates fully open cracks), at the top surface of the slab from (a) experiment (b) analysis at level III; (c) analysis at level IV; (d) analysis at level V.

The yielding and rupture of reinforcement was influenced by the bond-slip property. Figure 12 (up) presents the yielding pattern of reinforcement from the analyses at level III, IV and V. Two of the reinforcement bars, located at the centre of the slab, started to yield when the load in all analyses reached around $40 \mathrm{kN}$. Then, the number of elements in which the reinforcement yielded gradually increased at levels III, IV but and V. In all analyses, the stress in the reinforcement bars continuously increased until the descending branch, indicating reinforcement rupture. 


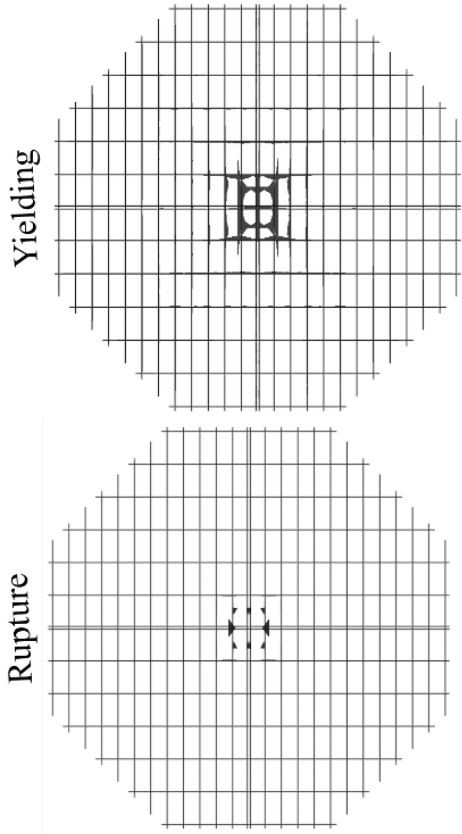

Level III
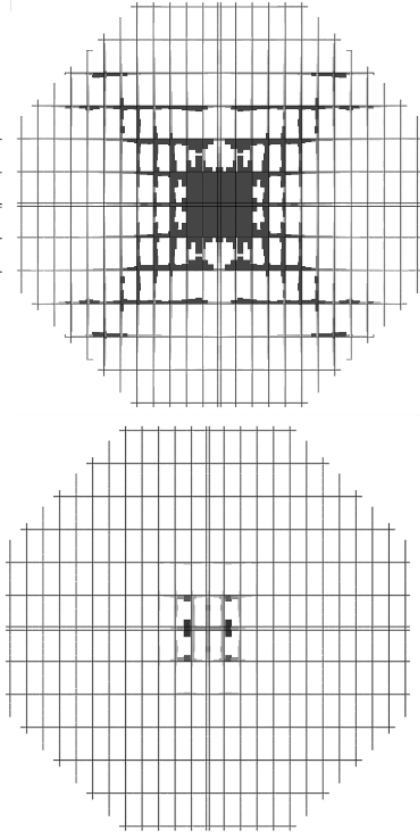

Level IV
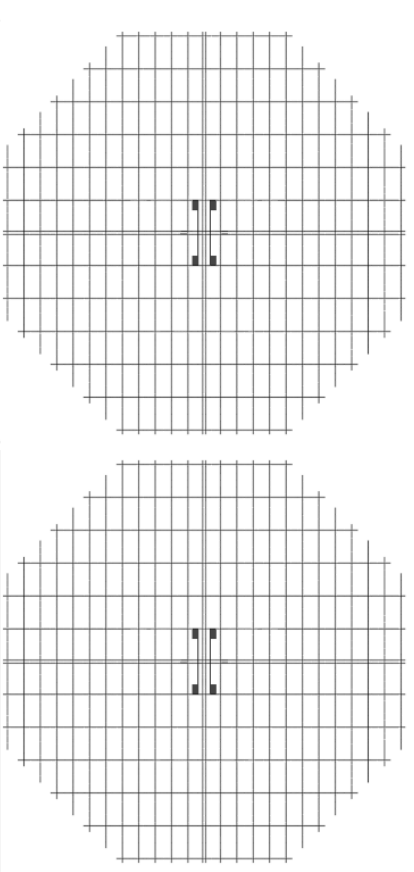

Level V

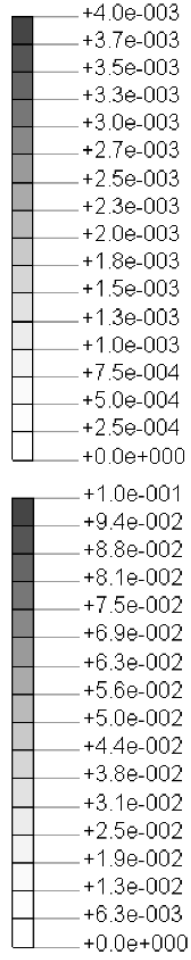

Figure 12. The strain based yielding pattern from analysis of the two-way slabs at $95 \%$ of the ultimate load ( $\varepsilon_{y}=4 e-3$ indicates yielding) of reinforcement (top) and rupture pattern ( $\varepsilon_{y}=1 e-1$ indicates rupture) of reinforcement (bottom)

\subsubsection{Load-carrying capacity}

Figure 13 summarizes the load-carrying capacity based on the analysis of the different assessment levels and the experimental tests of the slabs. It is obvious that the detectable loadcarrying capacity increased for higher levels of assessment, but was always lower than the experimental value. The lowest resistance obtained was from analytical calculations according to the yield line theory (Level I). The linear FE model (Level II) resulted in a higher capacity than level I. On this level, the reinforcement moments obtained from the linear analysis were redistributed over an effective width. However, the redistribution widths according to the recommendations by (Pacoste et al., 2012) are intended to be conservative estimates. Therefore, for assessment of existing structures, it is important to choose the effective widths according to how the reinforcement is distributed in the slab. A lower load-carrying capacity was estimated at levels I and II than levels III-V due to two major reasons. On one hand the hardening of reinforcement steel was not included in the resistance model at the lower levels. On the other hand, the membrane action of the slab was not reflected at the lower level but included in the FE analyses at higher levels. Compared to linear FE shell analysis (level II), non-linear FE shell analysis (level III) increase the capacity considerably since it includes material non-linearity. In addition, a load-deflection response was obtained with this level of analysis. The crack pattern was also visible so that where and how the slab gets damaged and fails were recognizable. Compared to the non-linear FE shell model, the non-linear FE continuum element models (levels IV-V) predicted the capacity more accurately. One reason to this probably is because the geometric non-linearity was included in the continuum element model of the slab. The slab had a significant deflection during the test, arriving at $120 \mathrm{~mm}$, greater than the thickness itself. By including the geometric non-linearity, the membrane action was accounted for more correctly at large deflections. Figure 13 shows that the load carrying capacity predicted at level V was slightly lower that that predicted at level IV. The 
explanation for this is that when reinforcement slip was included, the strain in the reinforcement in regions with localised cracking became larger than with fully bonded reinforcement, for the same load level. Thus, the reinforcement reached rupture earlier in the analysis at level $\mathrm{V}$ than in the level IV analysis.

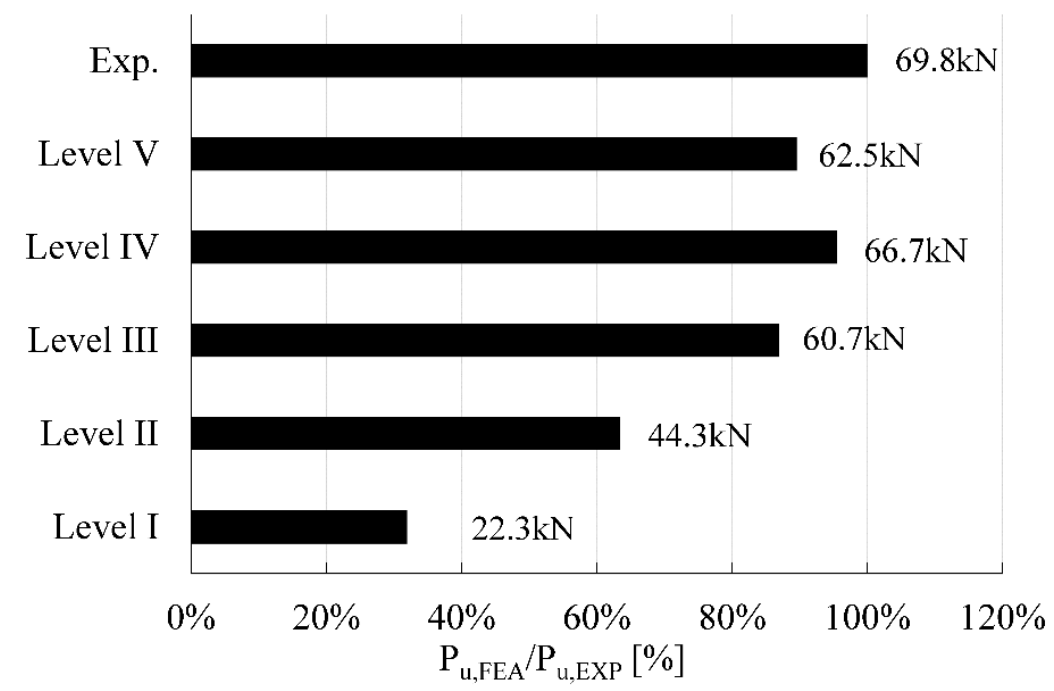

Figure 13. Load-carrying capacity, limited by bending failure, of the two-way slabs with assessment at different levels, compared with experimental results.

\section{Case 2: Application to a Cantilever Slab Test}

\subsection{Experiment}

To investigate the structural behaviour and failure mode of cantilever bridge deck slabs, several experiments have been performed (Vaz Rodrigues, Fernández Ruiz, \& Muttoni, 2008). The experimental work involved six experiments on two specimens, representing the cantilever deck slab of a box girder bridge in $3 / 4$ s scale, without shear reinforcement in the slab. A slab with four concentrated loads, slab DR1-a, was chosen for the study in this paper, see Figure 14(a). The cantilever had a span of $2.78 \mathrm{~m}$ and a length of $10 \mathrm{~m}$. The slab thickness varied from $0.38 \mathrm{~m}$ at the supported end to $0.19 \mathrm{~m}$ at the cantilever tip as shown in Figure 14 (b\&c). The fixed end support was clamped by means of vertical pre-stressing. The reinforcement layout is displayed. The specimen was subjected to four concentrated forces simulating traffic loads. The concentrated loads were applied on the top of the slab using steel plates with dimensions $300 \times 300 \times 30 \mathrm{~mm}$. The deflection at point $p$ was measured. Details regarding the cantilever test and the monitoring campaign can be found in Vaz Rodrigues et al. (2008). 


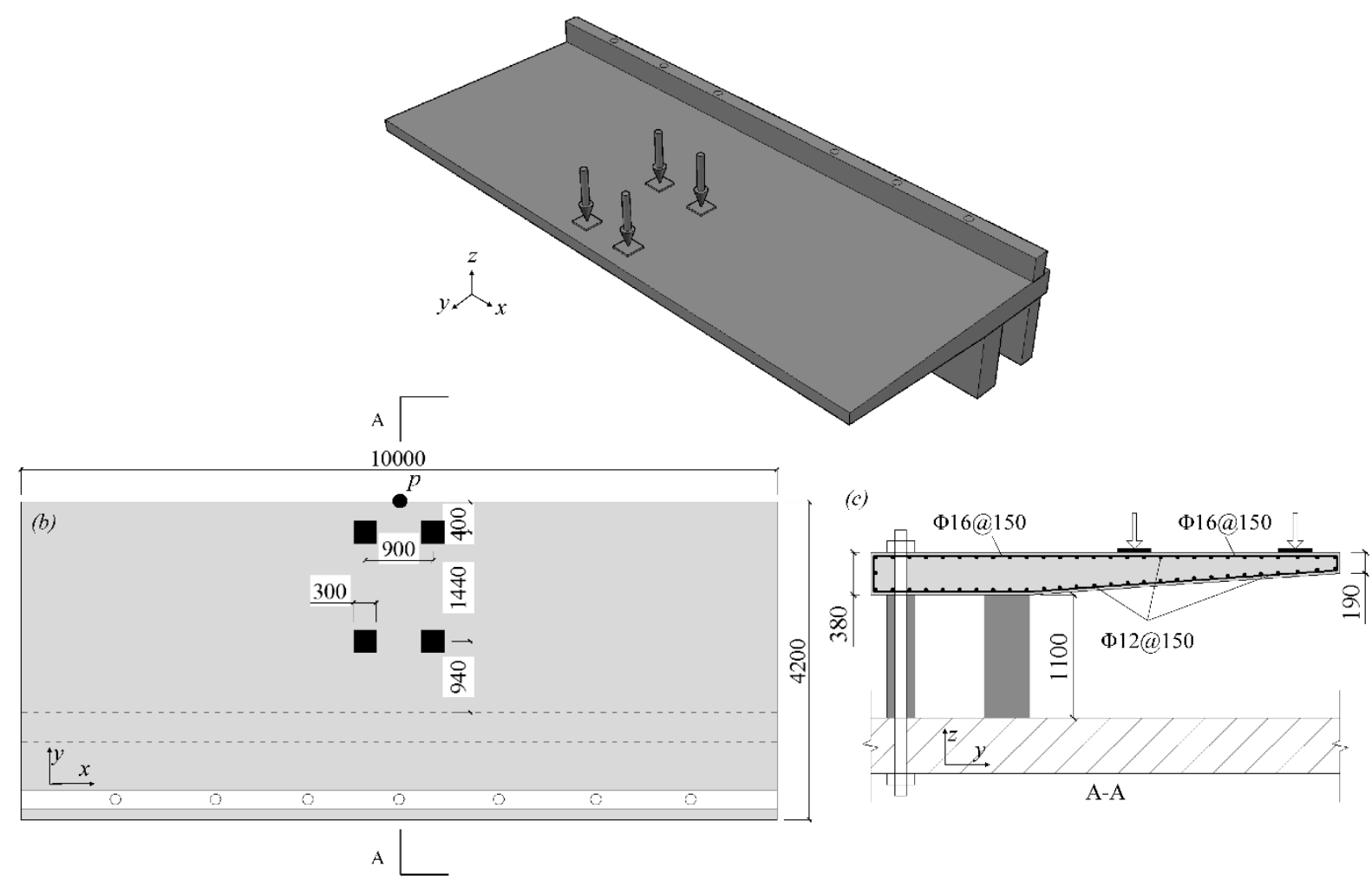

Figure 14. The experiment set-up, dimensions and reinforcement layout for cantilever slab DR1-a, adapted from (Vaz Rodrigues, 2007); (a) isometric view (b) top view and (c) cross section; all dimensions are in $\mathrm{mm}$

The specimen failed in a brittle manner at a total load of $Q_{u \text { uexp }}=1396 \mathrm{kN}$ by the development of a curved shear failure surface around the concentrated loads. The crack pattern at failure loads, includes flexural cracks at the top and bottom surface, and inclined shear cracks from the top towards the bottom the cantilever slab (Vaz Rodrigues et al., 2008).

\subsection{Analysis at Different Assessment Levels}

\subsubsection{Material Models for Concrete and Reinforcement}

In the following section, the cantilever slab has been evaluated at different assessment levels according to the proposed strategy in this paper. In all calculations, mean value of material parameters from the tests were used, see Table 3.

Table 3. Mean values of material parameters for the cantilever slab (Vaz Rodrigues, 2007).

\begin{tabular}{|l|l|l|c|}
\hline \multicolumn{2}{|l|}{ Parameter of concrete } & \multicolumn{3}{|c|}{ Parameter of reinforcement steel } \\
\hline Elastic modulus & $E_{c}=36.0 \mathrm{GPa}$ & Elastic modulus & $E_{s}=210 \mathrm{GPa}$ \\
\hline Poisson's ratio & $v=0.15$ & Poisson's ratio & $v=0.2$ \\
\hline Compressive strength & $f_{c m}=39.1 \mathrm{MPa}$ & Yield strength & $f_{y}=499 \mathrm{MPa}$ \\
\hline Tensile strength & $f_{c t m}=2.9 \mathrm{MPa}$ & Ultimate strength & $f_{u}=600 \mathrm{MPa}$ \\
\hline
\end{tabular}

The non-linear material model used in the cantilever slab model was similar to the one for the two-way slab, previously described in case study 1 . A total strain rotating crack model was used for the concrete and a Von Mises yield criterion was used for the reinforcement. The material properties available from the experiment were used and complemented with some assumptions regarding the material response. Linear tension softening after cracking and the Thorenfeldt (1987) compressive behaviour were used for concrete, while bi-linear hardening plasticity behaviour was adopted for reinforcement, see Figure 15. 

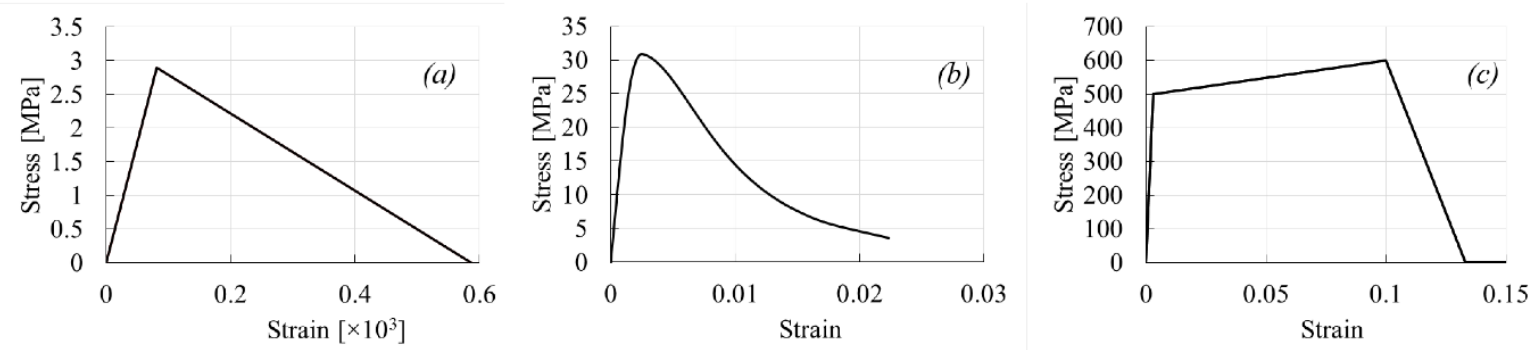

Figure 15. Examples of stress-strain relations used for material response in the cantilever slab, for (a) concrete in tension, (b) concrete in compression and (c) reinforcement steel.

\subsubsection{Level I: Simplified Analysis Method}

To assess the load-carrying capacity in the ultimate limit state, several possible failure mechanisms were evaluated such as (a) flexural failure, (b) one-way shear failure and (c) punching shear failure. The anchorage capacity, checked according to Eurocode 2 (EN 1992$1-1,2004)$, was found to be non-critical to this case. The flexural load-carrying capacity was checked using the yield line theory (Vaz Rodrigues, 2007), see Figure 16 (a). Resistance models for the one-way shear resistance and the punching shear resistance of flat slabs are provided by Eurocode 2 (EN 1992-1-1, 2004), see Figure 16 (b) \& (c). In all models, the design shear strength $V_{R}$ is estimated by multiplying a shear strength per unit length (nominal shear strength $v_{R}$ ) by a control perimeter $\left(\mathrm{b}_{0}\right)$. For a group of four loads, simulating vehicle loads, a critical control perimeter may be in section 1 or 2, Figure 16 (c).
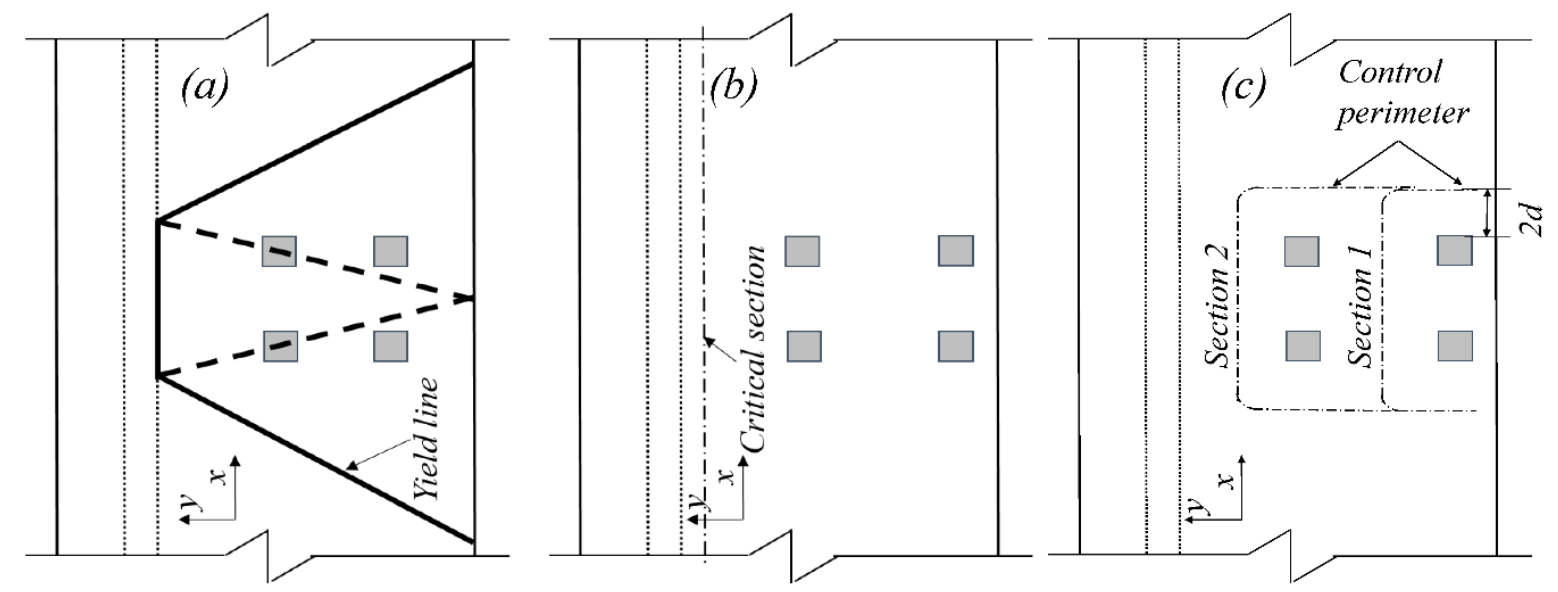

Figure 16. Resistance models used for the cantilever slab at level I: (a) yield line figure used for bending resistance, (b) critical section for one-way shear and (c) critical sections for punching shear

Calculation results show that the outer section 1 is more critical due to shorter perimeter and smaller effective depth. The resistance for bending, one-way shear and punching shear can be found in Table 4.

Table 4. Calculated load-carrying capacity for bending, one-way shear and punching shear *indicates the critical value

\begin{tabular}{|l|l|}
\hline Resistance & Load-carrying capacity $Q_{u}(\mathrm{kN})$ \\
\hline Bending capacity & 1600 \\
\hline One-way shear & 1650 \\
\hline Punching shear & $906^{*}$ \\
\hline
\end{tabular}


Thus the governing failure mode at this level is punching shear at section 1 and the loadcarrying capacity was $\mathrm{Q}_{u}=906 \mathrm{kN}$ at this level.

\subsubsection{Level II: 3D Linear Shell (FE) Analysis}

To determine the load effects by linear FE analysis in the cantilever RC slab, a 3D shell element model was created, see Figure 17. The dimensions in the FE model were identical to the experiment. The concrete slab was modelled with 8-noded rectangular shell elements at $100 \mathrm{~mm} \times 100 \mathrm{~mm}$ size. The boundary conditions were chosen to simulate the experimental conditions, with all translations fixed along edge $\mathrm{A}$, and the vertical translations fixed along the simply supported edge B. A unit load of $1 \mathrm{kN}$ was equally distributed over the four loading plates.

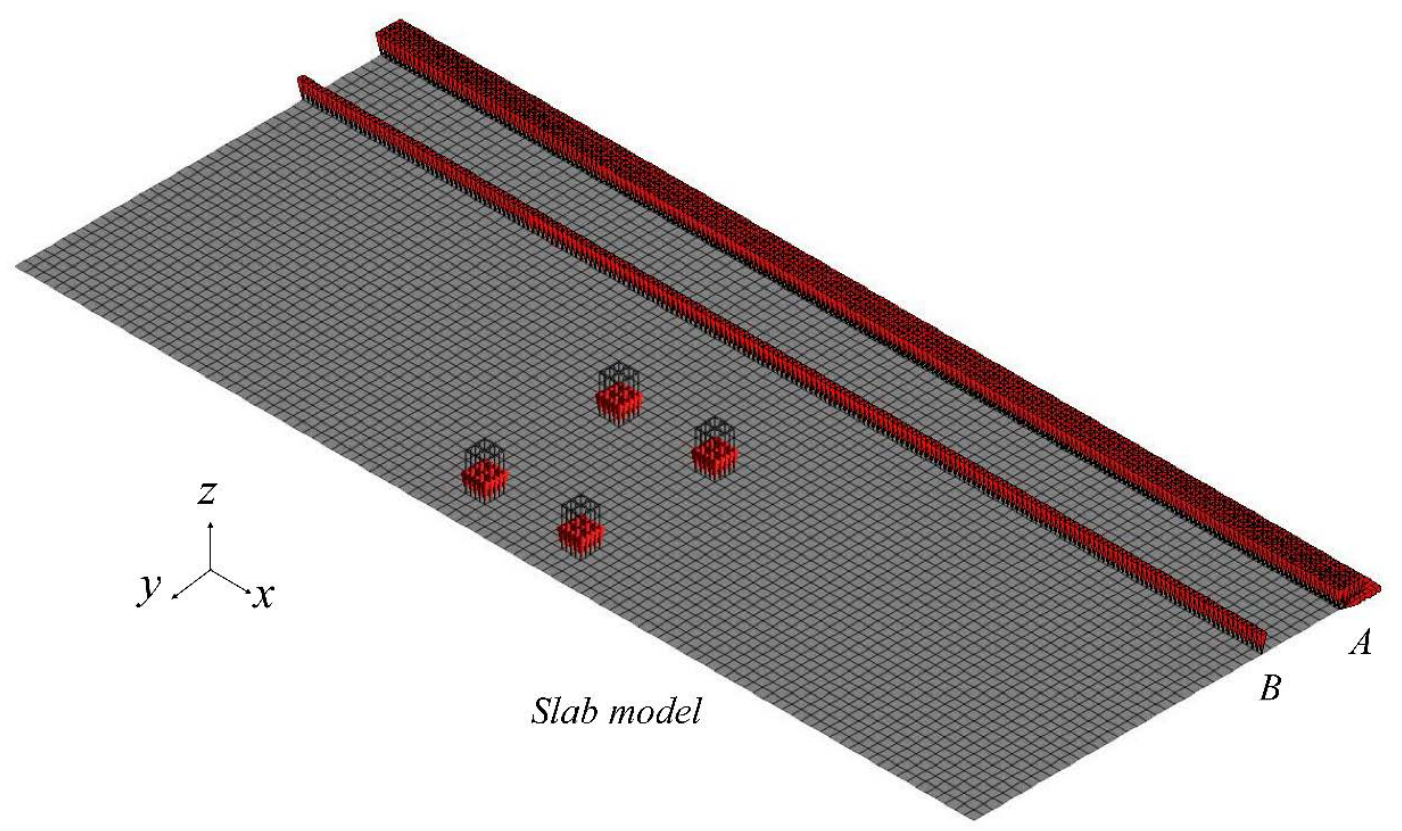

Figure 17. Linear shell element model of the cantilever RC slab, for level II

To analyse the one-way shear capacity, the shear force field from the linear FE analysis was used. According to (Pacoste et al., 2012), the critical cross-section for shear forces can always be chosen at a distance $y_{c s}=(c+d) / 2$ away from the centre of the loading plate. For the slab test studied this results in two possible critical cross sections as shown in Figure 18 (a). In Figure 18 (b), a typical shear force distribution obtained from linear FE analysis, for one of the critical sections, is shown. According to Pacoste (2012), the distribution width $w_{x}$ can be determined as:

$$
w_{x}=\min \left\{\begin{array}{c}
7 d+b+t \\
10 d+1.3 y_{c s}
\end{array}\right.
$$

Equation 5

where $d$ is the effective depth at the critical section, $t$ is the thickness of the surface and $b$ and $c$ are the dimensions of the loading plates, as shown in Figure 18. The shear resistance for sections 1 and 2 were calculated to be $967 \mathrm{kN}$ and $1015 \mathrm{kN}$, respectively. 


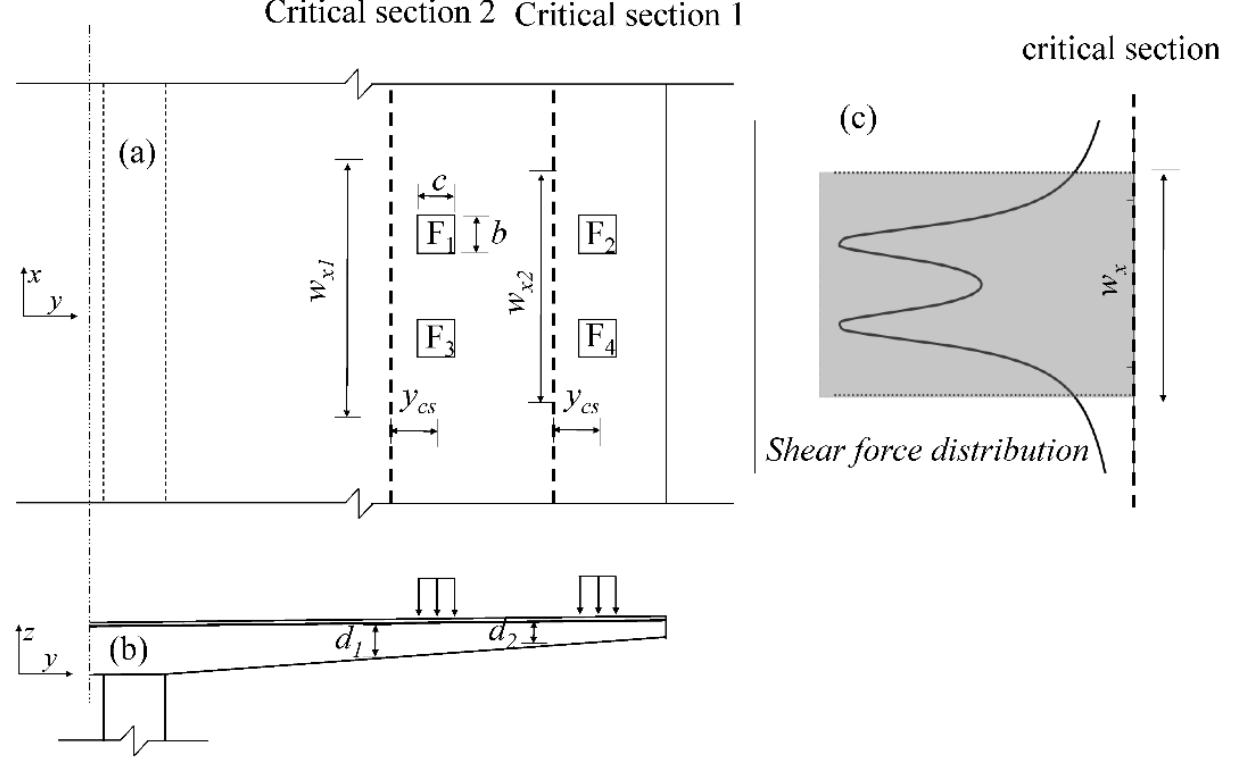

Figure 18. Schematic illustration of one-way shear assessment for the cantilever RC slab, using linear shell FE analysis at level II; (a) top view of cantilever slab, layout of loads, critical sections and shear distribution width w; (b) cross section of cantilever slab; (c) shear force distribution along critical sections.

The punching shear capacity with linear elastic analysis was calculated according to MC2010 (CEB-FIP, 2013). The design shear resistance attributed was taken as

$$
V_{R d . c}=k_{\psi} \sqrt{f_{c m}} b_{0} d_{v}
$$

Equation 6

The parameter $k_{\psi}$ depends on the rotations $\psi$ of the slab and $f_{c m}$ is the mean value of concrete compressive strength. $d_{v}$ is the effective depth of the slab and $b_{0}$ is the shear-resisting control perimeter. The way to calculate these parameters can be found in MC2010 (CEB-FIP, 2013). The results of this calculation have been summarized in Table 5.

Table 5: Load-carrying shear capacity of cantilever slab at level II

*indicates the critical value

\begin{tabular}{|l|l|l|}
\hline Load-carrying capacity $(\mathrm{kN})$ & One-way shear & Punching shear \\
\hline Section 1 & 1077 & 1167 \\
\hline Section 2 & 1055 & $1009^{*}$ \\
\hline
\end{tabular}

The bending capacity was also calculated and proved to be non-critical. Thus, the governing failure mode at this assessment level was punching shear at section 2 and the loadcarrying capacity was $\mathrm{Q}_{u}=1009 \mathrm{kN}$ at this level.

\subsubsection{Level III: 3D Non-linear Shell FE Analysis}

At level III, the slab was modelled with shell elements using the same FE mesh as in the level II analysis; see Figure 19, but with non-linear material response and fully bonded reinforcement. The integration scheme was identical to level III in case 1, i.e., Simpson integration with 9 integration points in the thickness direction. Furthermore, the boundary conditions at support B were modelled differently than for Level II; instead of fixing the vertical translations along a line, the supports, consisting of concrete blocks, were modelled using non-linear springs, representing the stiffness of the concrete blocks in compression and 
with low stiffness in tension to allow uplifting. The reinforcement was modelled as fully bonded embedded reinforcement grids in both $x$ and $y$ directions.

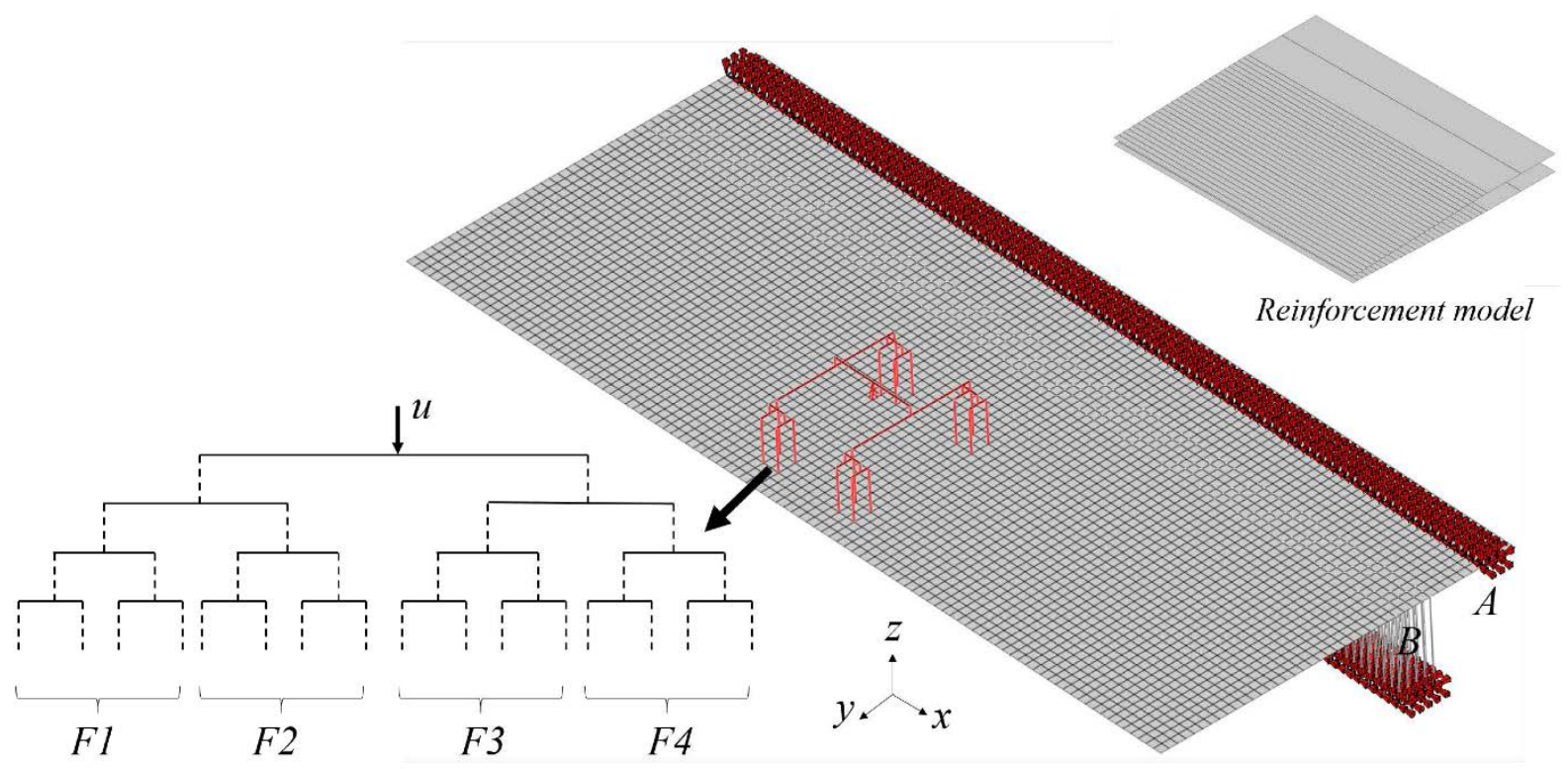

Figure 19. Non-linear shell element model of the cantilever RC slab, for level III.

To enable deformation control of the four concentrated loads on steel plates, a loading substructure was used in the model, see Figure 19. The loading sub-structure was modelled with very stiff beam elements, and was designed to be statically determinate. The stiff beams were connected by tying some of the nodes to each other, (the dashed lines in Figure 19), so that they had the same translation in z-direction. This way, the load was distributed equally on 16 nodes, each concentred load in the test represented by four node loads. The analysis was carried out using a regular Newton-Raphson iteration method based on force and energy convergence criteria, with a tolerance of 1e-2. In the experiment, cyclic loading was included in to investigate the structural behaviour at SLS (Vaz Rodrigues, 2007).However, in the FE analysis, the cyclic loading was not included to avoid numerical difficulties and because the structural behaviour at ULS was of primary interest in this study. The analysis finished when it could not reach convergence due to reinforcement rupture, indicating a bending failure, at a load level of $1683 \mathrm{kN}$.

Since shear type failures are not reflected in the analysis at this level, the resistance with respect to one-way shear and punching was separately evaluated. The governing punching capacity was calculated using the results from the non-linear FE analysis by applying the critical shear crack theory (CSCT) by Muttoni (2009), according to MC2010 (CEB-FIP, 2013). In this method, the punching shear strength $V_{R}$ depends on the rotation $\psi$ of the slab. The punching capacity for both critical sections 1 and 2 were checked, see Figure 20(a). The difference in rotations between points $p_{1}$ and $p_{2}$ (see Figure 20(a)) was used for critical section 2; while the difference in rotations between points $p_{2}$ and $p_{3}$ (see Figure 20(a)) was used for critical section 1 . The failure loads were determined as the intersection point between the relation for the relative shear force versus rotation obtained from the non-linear FE analysis and the corresponding failure criterion according to Figure 20(b). The results show that the punching capacity, instead of bending and one way shear, was found to limit the load-carrying capacity of the slab to $Q_{u}=1229 \mathrm{kN}$. 


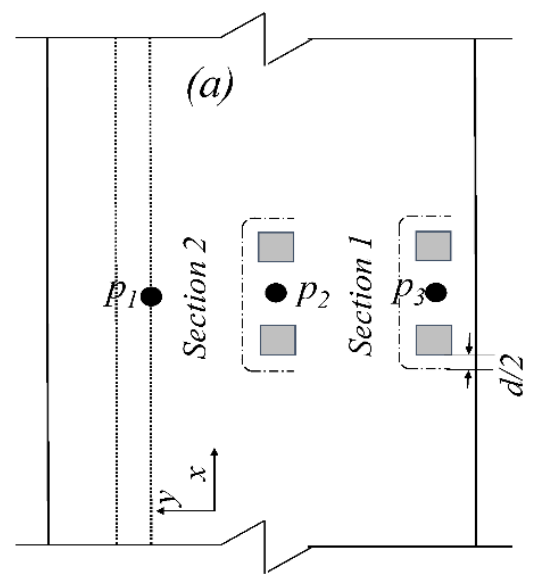

Failure criterion: $\frac{V_{R}}{\mathrm{~b}_{0} d \sqrt{f_{c}}}=\frac{3 / 4}{1+15 \Psi d /\left(d_{g 0}+d_{g}\right)}$

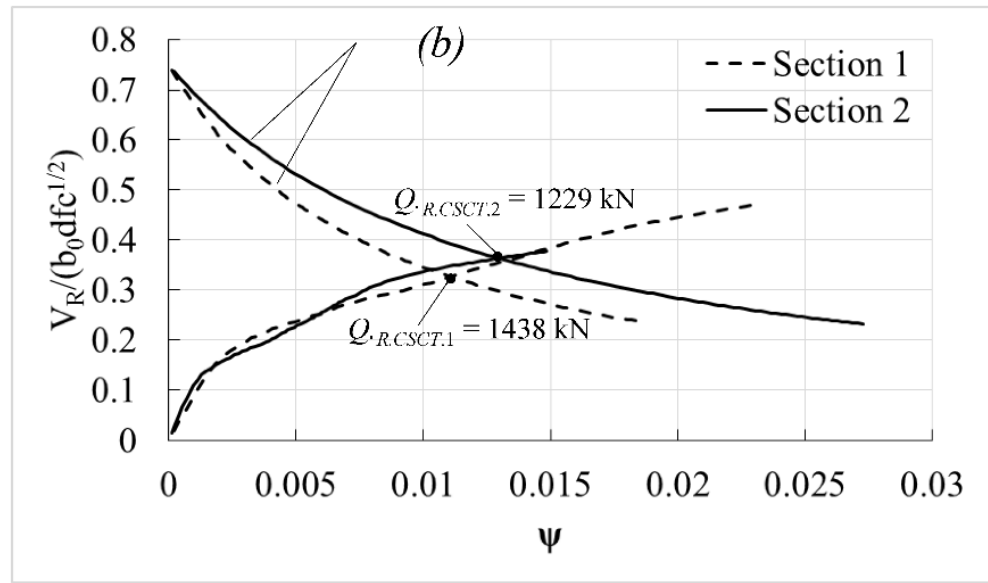

Figure 20. Determination of shear punching resistance based on the Critical Shear Crack Theory (CSCT) (Muttoni, 2009) for the cantilever RC slab; (a) location of points $p_{1}, p_{2}, p_{3}$ and critical sections (b) load-rotation curve and failure criterion

\subsubsection{Level IV: 3D Non-linear FE Analysis with Continuum Elements and Fully Bonded Reinforcement}

In order to capture the inclined cracking and shear failure, a detailed 3D model of half of the slab was created for the assessment at level IV using continuum elements, as displayed in Figure 21. In this FE model, the steel plates along edge A under the hydraulic jacks of the loading system, used in the test, were included in the model. The supporting concrete blocks along line $\mathrm{B}$ were also included, with interface elements between the blocks and the slab to describe friction. Second order 8-noded brick elements, $150 \times 150 \times 60 \mathrm{~mm}$ (length $\times$ width $\times$ height) were used. Further refinement of the element mesh was found to have minor impact on the analyses results (Shu et al., 2014a). In contrast to case study 1 , first order elements were not used to prevent the analysis from becoming too time consuming (Shu et al., 2014a; Hendriks et al., 2012); three elements instead of eight were used over the height, resulting in approximately $1 / 10$ of the elements . The translations of all nodes at the symmetry faces were fixed in the direction perpendicular to the faces. The steel plates along edge $\mathrm{A}$ had fixed translations for vertical direction, and the concrete block at position B was simply supported at its lower face. A loading sub-structure, as described at level III, was included also in this model. Each reinforcement bar of the slab was modelled as a fully bonded embedded reinforcement bar, but two layers of reinforcement are overlapped in Figure 21. The analysis was carried out using a regular Newton-Raphson iteration method based on force and energy convergence criteria, with a tolerance of 1e-2. The analysis finished when a shear type failure with an inclined shear surface was formed. The response and failure are further discussed in section 5.3. The load-carrying capacity obtained was $Q_{u}=1260 \mathrm{kN}$. 


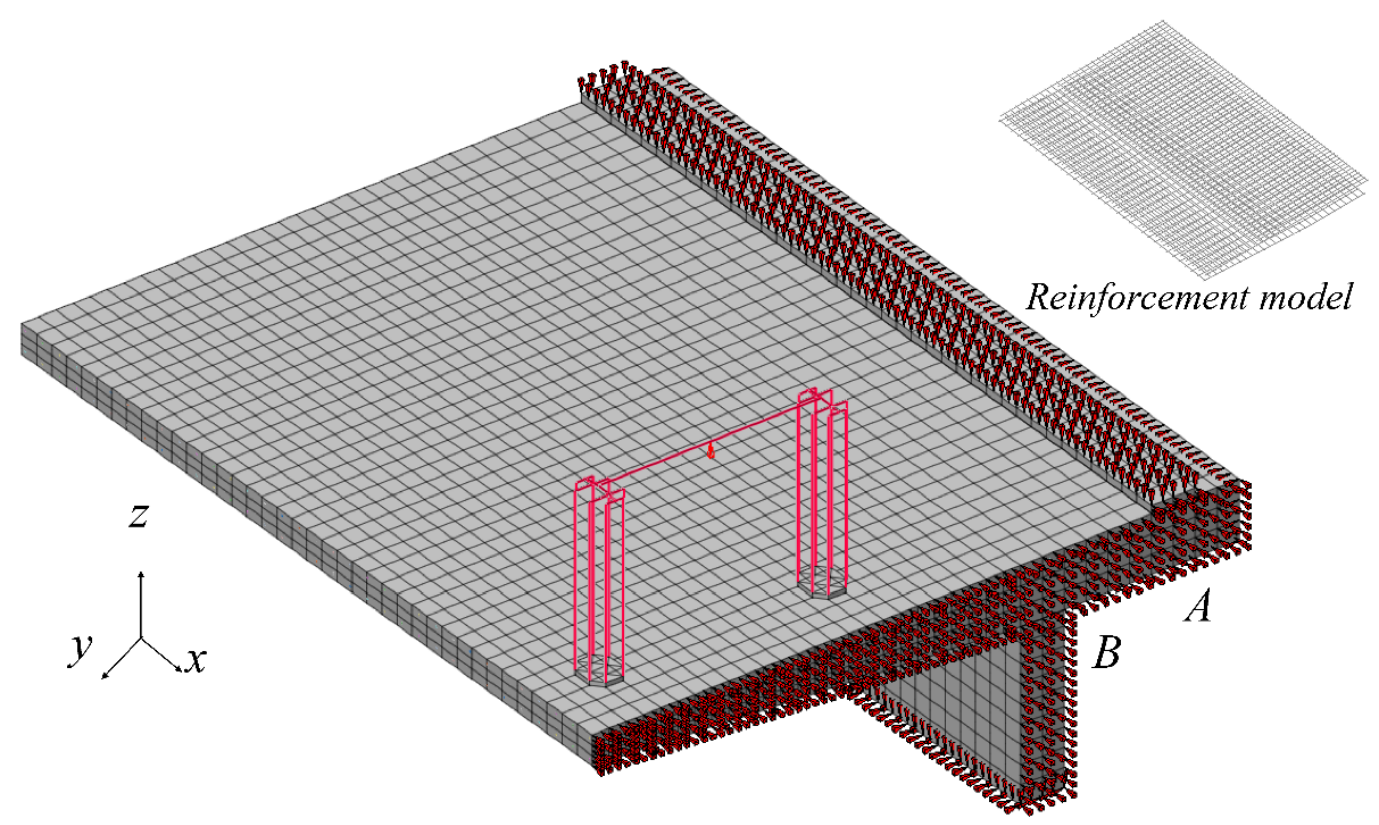

Figure 21. Non-linear continuum element model of cantilever RC slab, for level IV.

\subsubsection{Level V: 3D Non-linear FE Analysis with Continuum Elements Including Reinforcement Slip}

The model at level V \& IV were identical except for the reinforcement. Instead of using fully bonded reinforcement, an assumed bond-slip relation was included to describe the interaction between the reinforcement and surrounding concrete more in detail. The bond-slip property used was based on MC1990 (CEB-FIP, 1993); see Figure 9, with maximum bond stress 12.5MPa. The analysis finished when a shear type failure with an inclined shear surface was formed and the load-carrying capacity obtained at this level was $Q_{u}=1269 \mathrm{kN}$.

\subsection{Result and Discussion}

\subsubsection{Structural Behaviour}

The ultimate load capacity of the cantilever slab at assessment level I-II and the load deflection curves from both the non-linear FE analyses at levels III-V and the experiment are displayed in Figure 22. Figure 23 shows the crack patterns from both the experiment and the non-linear FE analyses at $95 \%$ of the ultimate load. It is evident that the load-deflection behaviour from the analyses at level III-V are in good agreement with experimental results, except for deflections smaller than around $20 \mathrm{~mm}$ where the analyses show higher loads than the experiment. The seemingly more flexible response in the experiment is a consequence of that the slab was subjected to 100 loading cycles up to $410 \mathrm{kN}$ to investigate the behaviour at service limit state before finally loaded up to failure; this cyclic loading was not included in the analyses explaining the discrepancy in deflection for smaller loads. The cracks at the top surface developed in a semi-circular shape around the loads, resembling the crack pattern expected by the yield line theory mechanism at the ultimate load stage, see Figure 23. This indicates that the slab displayed bending behaviour at this stage. Figure 23 (b) (c) and (d) show contour plots of the largest principal strain at the top surface indicating the crack pattern at $95 \%$ of the ultimate load from the non-linear FE analyses at levels III-V. 


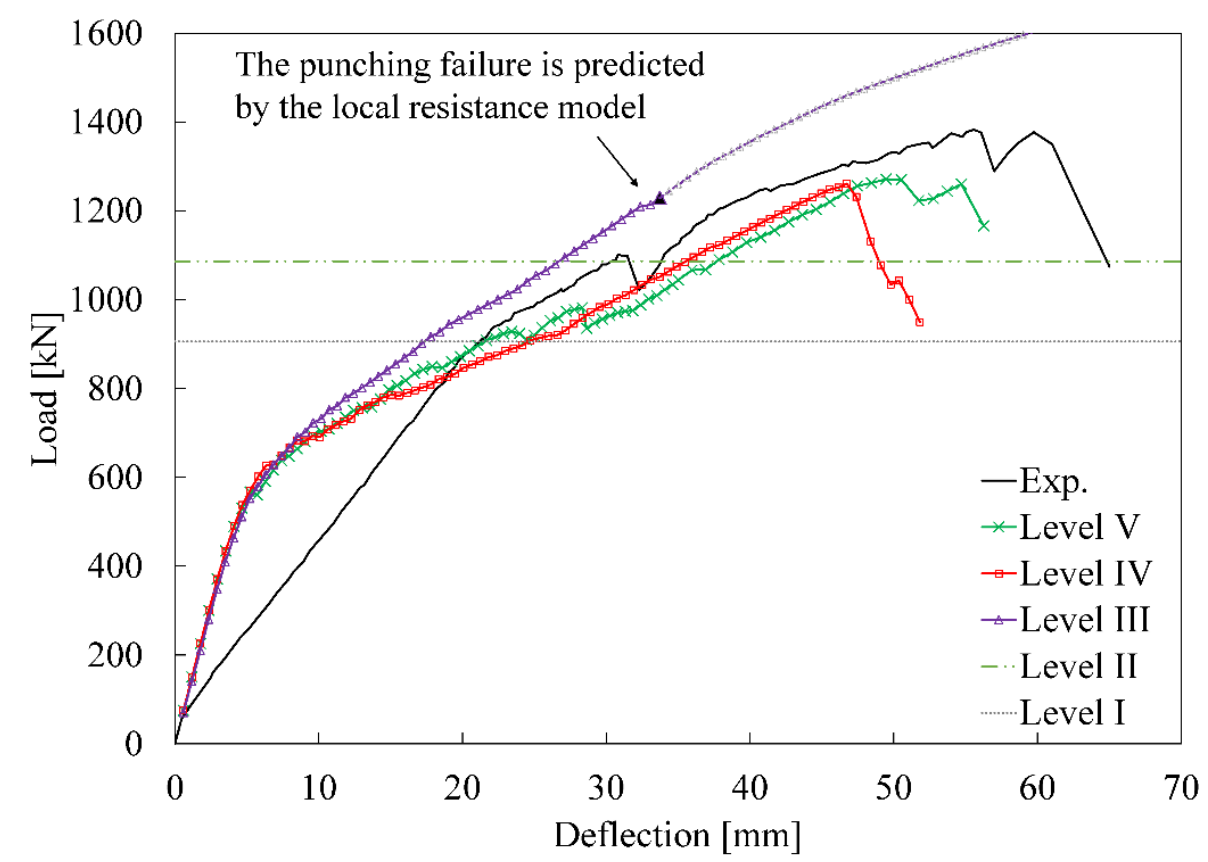

Figure 22. Load-deflection response and load carrying capacity for cantilever RC slab.

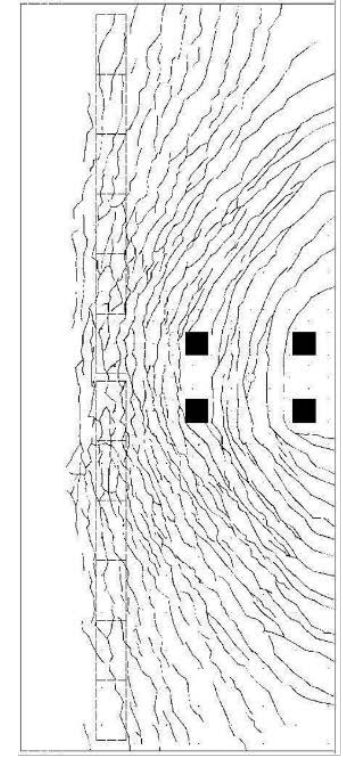

(a)

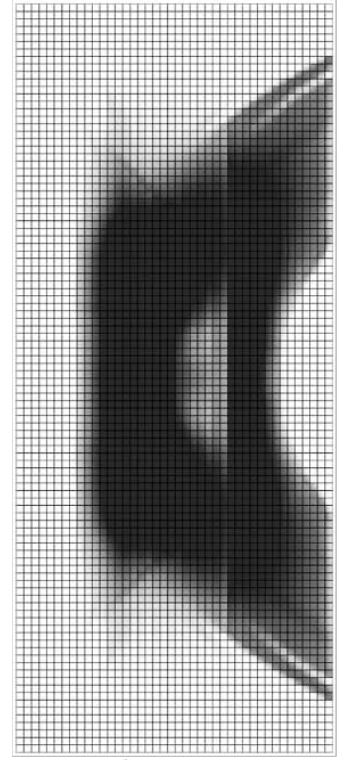

(b)

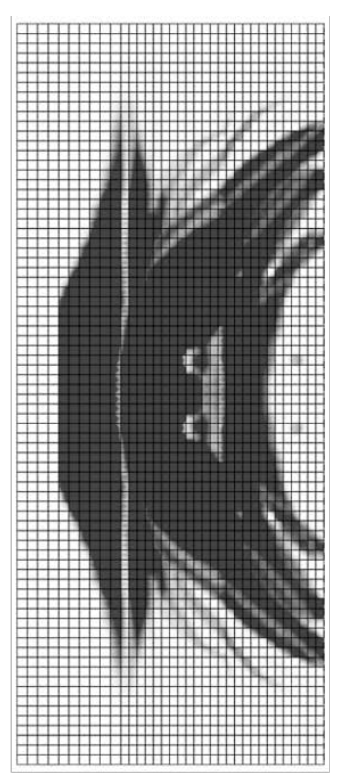

(C)

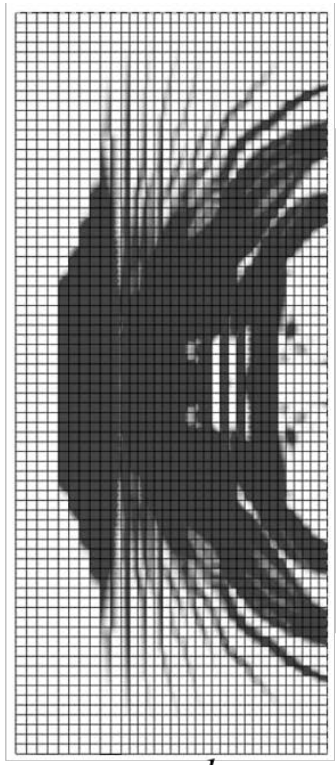

(d)

Figure 23. Crack pattern from experiment and strain based crack pattern from analysis of the cantilever RC slab at $95 \%$ of the ultimate load ( $\varepsilon=2 \mathrm{e}-3$ indicates elements with fully open cracks), at the top surface of the slab from (a) experiment, adapted from (Vaz Rodrigues), (b) analysis at level III; (c) analysis at level IV; (d) analysis at level V.

Meanwhile, an inclined shear crack developed around the two concentrated loads closest to the tip of the cantilever at a load level of about $Q=825 \mathrm{kN}$ (approximately $60 \%$ of ultimate capacity), corresponding well with the experiment results. This provoked the failure of the slab in a way similar to the experiment, see Figure 24. Another shear crack developed in the region between the clamped edge and the concentrated loads. This latter crack, however, did not develop to a complete failure surface. The shear cracks did not occur at level III as shell elements cannot describe shear cracking in the cross-section. Compared to level IV, the analysis at level V displayed a clearer crack pattern, but a similar structural behaviour. The 
experiment failed at a load of $Q_{u \cdot \exp }=1396 \mathrm{kN}$ in a shear manner, which is higher than at levels IV - V.

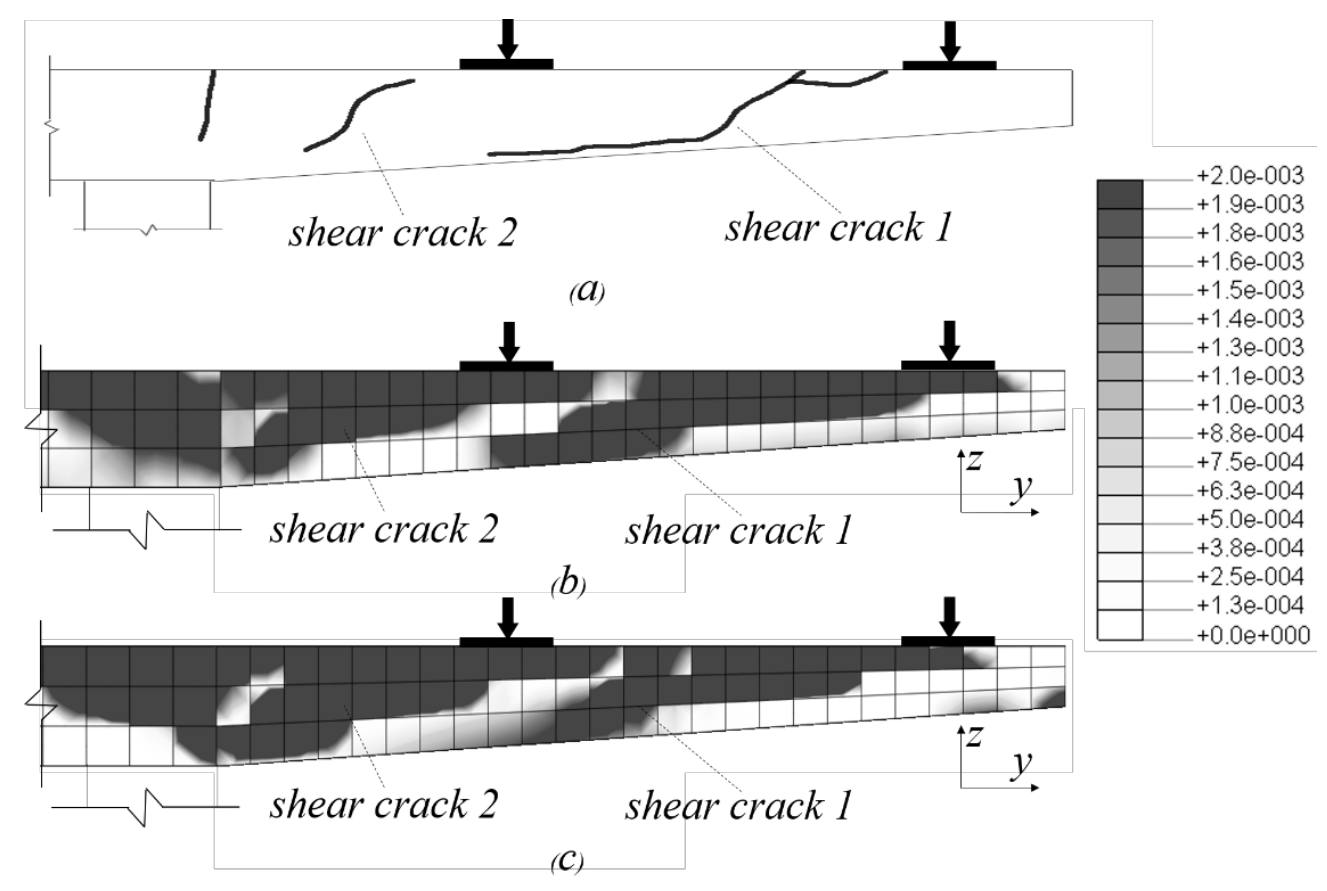

Figure 24. Strain based crack pattern at section A-A (see Figure 14) from analysis of the cantilever RC slab at $95 \%$ of the ultimate load ( $\varepsilon=2 \mathrm{e}-3$ indicates fully open crack) from $(a)$ experiment, adapted from (Vaz Rodrigues), (b) analysis at level IV; (c) analysis at level V.

The influence of flexural cracks on the shear force distribution was also observed when shifting from linear to non-linear FE analysis. Shams Hakimi (2012) indicated that the shear stress along the support became more evenly distributed when the non-linear flexural response was taken into account, see the shear force distribution from levels II and III in Figure 25. This was because the initial flexural crack started at the mid region, which forced the shear force to be redistributed away from the crack region, i.e., to be moved outwards from the middle. Since plastic redistribution reduced the shear from what was predicted from linear analysis, it is beneficial if structures sensitive to shear are assessed taking this into account. Based on the measured crack widths in the experiment, yielding occurred both on the top and on the bottom reinforcement before punching failure occurred (Vaz Rodrigues, 2007). Consequently, the load was redistributed, as the slab was capable of carrying increasing loads after yielding of the reinforcement. However, in the non-linear analyses, yielding of the reinforcement was observed only in the analysis at level V, but not at levels III and IV. The reason was that at level III and IV, the strain of the reinforcement was limited by the full bond to surrounding concrete. In the non-linear FE analysis at level V, this restriction did not exist. 


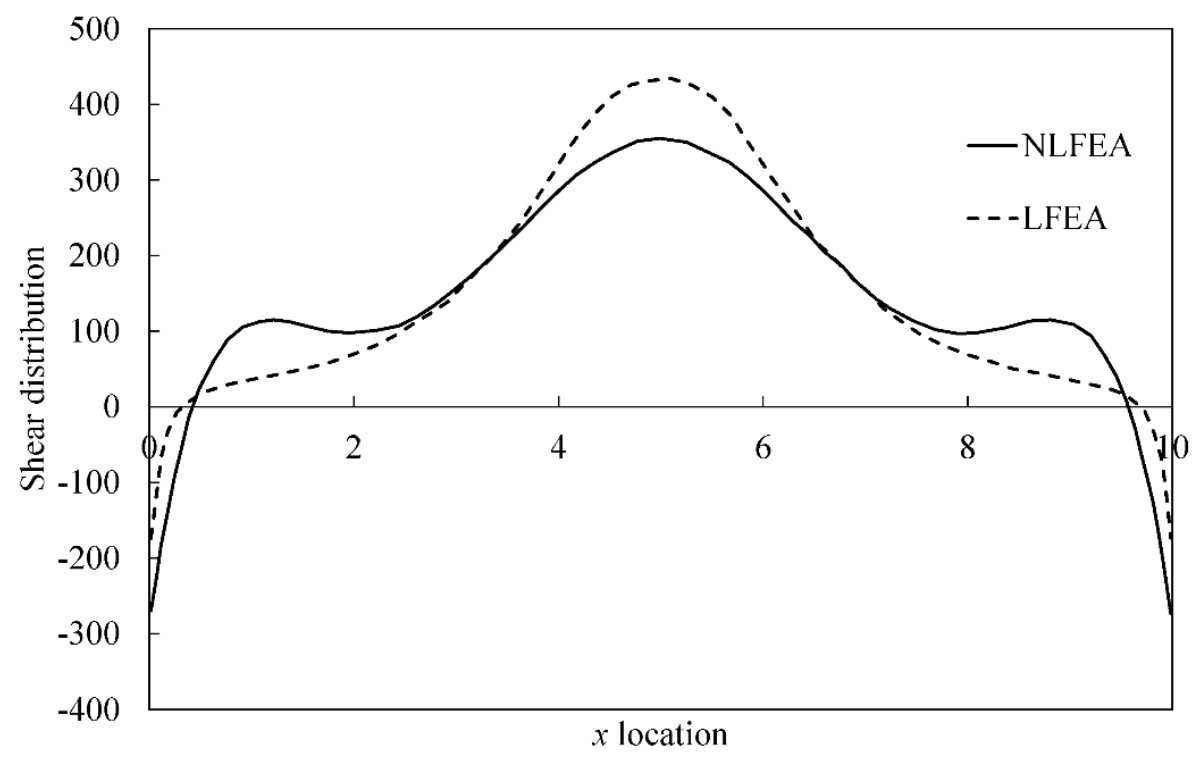

Figure 25. Shear force distribution along supports from model at level II and III (Hakimi, 2012).

\subsubsection{Load-carrying Capacity}

Figure 26 summarizes the ultimate loads from all assessment levels and from the experiment for the bridge cantilever slab. Generally, the predicted capacity increased for higher levels, but was always smaller than the experimental value. The lowest resistance was obtained from analytical calculations according to Eurocode 2 (level I). The linear FE analysis (level II) resulted in a slightly higher prediction. At this level, a distribution of the shear force from linear FE model could be made by assuming a distributed width. The assessment at levels I and II underestimated the load-carrying capacity partly because the redistribution of shear forces due to the cracking was not included in the structural analysis. However, a major reason that the non-linear FE shell analysis (level III) estimated the punching capacity better than the linear FE shell analysis (level II) is that the non-linear response from the structural analysis is included in the resistance model. However, it is important to note that even though the flexural crack pattern was reflected in analyses at level III, shear cracking in the crosssections cannot be reflected. Therefore the non-linear FE continuum element analyses (Level IV and Level V), which were capable of simulating punching failure and shear crack pattern, offered enhanced opportunity to accurately assess the RC slab subjected to shear. When the bond-slip properties of the reinforcement bars were included in the continuum element model (level V), the deformation of the structure and the interaction between the reinforcement and surrounding concrete could be reproduced closer to the reality. 


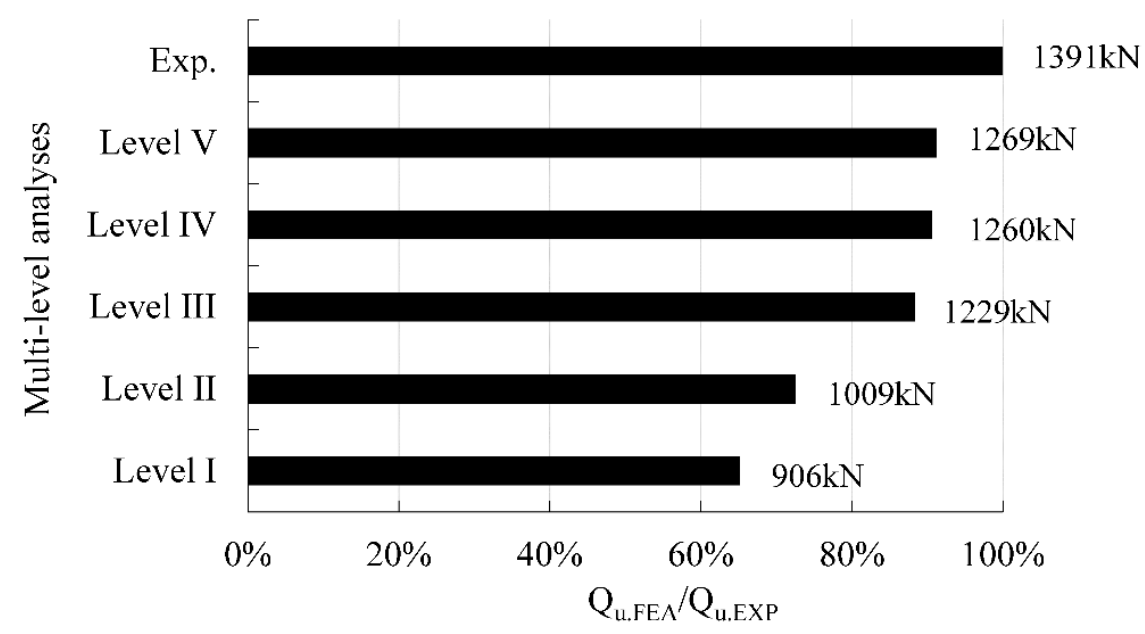

Figure 26. Load-carrying capacity, limited by punching shear, of the cantilever RC slab DR1-a with assessment at different levels, compared with experimental results.

\section{Conclusions}

This paper proposes a novel multi-level assessment strategy for reinforced concrete bridge deck slabs. The strategy is based on the principle of successively improved evaluation in structural assessment. The strategy is described in detail in section 3, including recommendations for analysis on the different assessment levels. The proposed strategy was evaluated on two case studies: (a) previously tested two-way slabs subjected to bending failure (Fall et al., 2014) and (b) a cantilever slab subjected to shear type failure (Vaz Rodrigues, 2007), in both cases loaded with concentrated loads.

The proposed strategy provides the engineering community a framework for using successively improved structural analysis methods for enhanced assessment in a straight forward manner. The study shows that the proposed assessment strategy and analysis methods are valid and give conservative estimates of the load carrying capacity. Even though it was demonstrated on simple structures tested in laboratory only, the strategy is intended and suited for assessment of real full-scale structures like bridge deck slabs in engineering practice. As expected, the case studies show that more advanced methods yield an improved understanding of the structural response and are capable of demonstrating higher, yet conservative, predictions of the load-carrying capacity. Furthermore, the case studies demonstrates that:

- Compared to linear analysis (levels I \& II), non-linear FE analysis (levels III, IV and V) has several advantages. In addition to detect higher load carrying capacity, such analysis gives improved understanding of the structural response for RC slabs because e.g. the load-deflection response and crack pattern are obtained from the analysis, and it is possible to witness where and how the slab failed.

- For slabs subjected to both shear and bending, the non-linear FE analyses (levels III, IV and V) are capable of reflecting interaction between bending and shear. Furthermore, nonlinear FE analyses with continuum elements (levels IV and V) are capable of reflecting inclined shear cracks and shear type failures, including punching.

- The case studies indicate that the largest improvement in detectable load carrying capacity can be obtained when using non-linear shell FE analysis (level III) instead of linear analysis (level II). This was observed not only for bending failure, but also for shear type failure when combined with more advanced resistance models according to MC2010 (CEB-FIP, 2013). However this needs to be verified through more case studies. 
In this study, the multi-level assessment strategy was applied to relatively simple structures. In the future, the proposed assessment strategy will be applied to and further developed for more complex structures. The application of the safety formats for non-linear analysis needs also to be further developed for more complex structures and failure modes. Furthermore, the multi-level assessment strategy needs to be integrated into a decision support system for the structural assessment, including inspection, testing, monitoring, reliability and risk analysis.

\section{Acknowledgement}

The authors would like to gratefully acknowledge the support and funding from Swedish Transport Administration (Trafikverket), which made the research possible.

\section{References}

ACI Committee 318. (2011). Building Code Requirements for Structural Concrete and Commentary. Farmington Hills, Mich: ACI American Concrete Institute.

Amir, S. (2014). Compressive membrane action in prestressed concrete deck slabs. $\mathrm{PhD}$ Thesis. Delft University of Technology, Delft, the Netherlands.

BBK 04. (2004). Boverkets Handbok om Betongkonstruktioner. Vällingby: ISBN 91-7147816-7.

Belletti, B., Damoni, C., Hendriks, M., \& Boer, A. de. (2014). Analytical and numerical evaluation of the design shear resistance of reinforced concrete slabs. Structural Conrete.

Blaauwendraad, J. (2010). Plates and FEM: Surprises and Pitfalls (ISBN 978-9.). Springer Science, Business Media B.V.

Boverket. (2004). Boverkets handbok om betongkonstruktioner. Vällingby: ISBN 91-7147816-7.

Broo, H., Lundgren, K., \& Plos, M. (2008). A guide to non-linear finite element modelling of shear and torsion in concrete bridges. Gothenburg.

CEB-FIP. (1993). fib Model Code for Concrete Structures 1990. Lausanne, Switzerland.

CEB-FIP. (2008). fib Bulletin No. 45: Practitioners' guide to finite element modelling of reinforced concrete structures. International Federation for Structural Concrete (fib).

CEB-FIP. (2013). fib Model Code for Concrete Structures 2010. Lausanne, Switzerland.

EN 1990. (2002). Eurocode - Basis of structural design.

EN 1992-1-1. (2004). Eurocode 2: Design of concrete structures - part 1-1: General rules and rules for buildings. Brussels, Belgium: CEN European Committee for Standardization.

EN 1992-2. (2004). Eurocode 2: Design of concrete structures - Part 2: Concrete Bridges Design and detailing rules. Brussels, Belgium: CEN European Committee for Standardization. 
Fall, D., Shu, J., Rempling, R., Lundgren, K., \& Zandi, K. (2014). Two-way slabs: Experimental investigation of load redistributions in steel fibre reinforced concrete. Engineering Structures, 80, 61-74. doi:10.1016/j.engstruct.2014.08.033

Hakimi, P. S. (2012). Distribution of shear force in concrete slabs. Master Thesis, Chalmers University of Technology, Gothenburg, Sweden.

Hambly, E. C. (1976). Bridge Deck Behaviour (1st ed.). London \& New York: E \& FN SPON.

Hendriks, M. A. N., den Uijl, J. A., de Boer, A., Feenstr, P. H., Belletti, B., \& Damoni, C. (2012). Guidelines for nonlinear finite element analysis of concrete structures. Rijkswaterstaat Technisch Document RTD:1016:2012 (1st ed.). Rijkswaterstaat Centre for Infrastructure.

Hillerborg, A. (1996). Strip method design handbook. London, Great Britain: Technology \& Engineering.

Jirásek, M. (2012). Modeling of localized inelastic deformation. Prague.

Johansen, K. W. (1972). Yield-Line formulae for slabs. (ISBN 0-721.). London: Cement and Concrete Association.

Long, A. E., Henderson, G. D., \& Montgomery, F. R. (2001). Why assess the properties of near-surface concrete? Construction and Building Materials, 15(2-3), 65-79.

Lundgren, K., Kettil, P., Zandi, K., \& Schlune, H. (2012). Analytical model for the bond-slip behavior of corroded ribbed reinforcement. Structure and Infrastructure Engineering, 8(2), 157-169.

Mier, J. (1984). Strain-softening of concreie under multiaxial loading conditions. Eindhoven University of Technology.

Muttoni, A. (2009). Punching Shear Strength of Reinforced Concrete Slabs by Aurelio Muttoni. ACI Structural Journal, (105), 440-450.

Pacoste, C., Plos, M., \& Johansson, M. (2012). Recommendations for finite elemetn analysis for the design of reinforced concrete slabs. Stockholm: TRITA-BKN Rapport 114.

Rombach, G. A. (2004). Finite element design of concrete structures. Thomas Telford.

Rots, J. G. (1988). Computational modeling of concrete fracture. Delft University of Technology.

SB-4.5. (2007). Non-Linear Analysis and Remaining Fatigue Life of Reinforced Concrete Bridges; Sustainable Bridges.

SB-ICA. (2007). Guideline for Inspection and Condition Assessment; Sustainable bridges. Retrieved from www.sustainablebridges.net

SB-LRA. (2007). Guideline for Load and Resistance Assessment of Existing European 
Railway Bridges; Sustainable Bridges.

Schlune, H., Plos, M., \& Gylltoft, K. (2011). Safety formats for nonlinear analysis tested on concrete beams subjected to shear forces and bending moments. Engineering Structures, 33(8), 2350-2356. doi:10.1016/j.engstruct.2011.04.008

Schreppers, G. (2011). Embedded Reinforcements.

Schreppers, G. (2015). Bond-slip Reinforcements and Pile Foundations.

Shu, J. (2015). Structural Analysis of Existing RC Bridge Deck Slabs Structural Analysis of Existing RC Bridge Deck Slabs. Chalmers University of Technology, Gothenburg, Sweden.

Shu, J., Fall, D., Plos, M., Zandi, K., \& Lundgren, K. (2014a). Development of modelling strategies for two-way RC slabs. Engineering Structures, 101, 439-449.

Shu, J., Fall, D., Plos, M., Zandi, K., \& Lundgren, K. (2014b). Finite element modelling of two-way RC slabs with varying modelling choices. In The 10th fib International PhD Symposium in Civil Engineering (pp. 589-594). Quebec, Canada.

Thorenfeldt, E., Tomaszewicz, A., and Jensen, J. J. (1987). Mechanical properties of highstrength concrete and applications in design. In In Proc. Symp. Utilization of HighStrength Concrete.

TNO. (2012). Diana finite element analysis, User's Manual -- Release 9.4.4. TNO DIANA $B V$. Delft, Netherlands.

Vaz Rodrigues, R. (2007). Shear strength of reinforced concrete bridge deck slabs. PhD Thesis, École Polytechnique Fédérale de Lausanne, Lausanne, Switzerland.

Vaz Rodrigues, R., Fernández Ruiz, M., \& Muttoni, A. (2008). Shear strength of R/C bridge cantilever slabs. Engineering Structures, 30(11), 3024-3033.

Zandi Hanjari, K., Kettil, P., \& Lundgren, K. (2011). Analysis of mechanical behavior of corroded reinforced concrete structures. ACI Structural Journal, 108(108), 532-541.

Zandi Hanjari, K., Kettil, P., \& Lundgren, K. (2013). Modeling the Structural Behavior of Frost-damaged Reinforced Concrete Structures. Structure and Infrastructure Engineering, 9(5), 416-431.

Zandi Hanjari, K., Lundgren, K., \& Coronelli, D. (2011). Bond capacity of severely corroded bars with corroded stirrups. Magazine of Concrete Research, 63(12), 953-968. doi:10.1680/macr.10.00200

Zandi Hanjari, K., Utgenannt, P., \& Lundgren, K. (2011). Experimental study of the material and bond properties of frost-damaged concrete. Cement and Concrete Research, 41(3), 244-254. doi:10.1016/j.cemconres.2010.11.007 